\title{
D1 Dopamine Receptor-Mediated LTP at GABA Synapses Encodes Motivation to Self-Administer Cocaine in Rats
}

\author{
Michal Krawczyk, ${ }^{1}$ Xenos Mason, ${ }^{1}$ Julian DeBacker, ${ }^{1}$ Robyn Sharma, ${ }^{1}$ Catherine P. Normandeau, ${ }^{1}$ Emily R. Hawken, ${ }^{1}$ \\ Cynthia Di Prospero, ${ }^{1}$ Cindy Chiang, ${ }^{1}$ Audrey Martinez, ${ }^{2,3}$ Andrea A. Jones, ${ }^{1}$ Évelyne Doudnikoff, ${ }^{2,3}$ Stephanie Caille, ${ }^{5,6}$ \\ Erwan Bézard, ${ }^{2,3}$ François Georges, ${ }^{3,4}$ and Éric C. Dumont ${ }^{1}$ \\ ${ }^{1}$ Department of Biomedical and Molecular Sciences and Center for Neuroscience Studies, Queen's University, Kingston, Ontario K7 L 3N6, Canada, \\ ${ }^{2}$ Université de Bordeaux, Institut des Maladies Neurodégénératives, UMR 5293, ${ }^{3}$ Université de Bordeaux, Interdisciplinary Institute for Neuroscience, UMR \\ 5297, and ${ }^{4}$ Centre National de la Recherche Scientifique, Interdisciplinary Institute for Neuroscience, UMR 5297, F-33000 Bordeaux, France, ${ }^{5}$ Université de \\ Bordeaux, Aquitaine Institute for Cognitive and Integrative Neuroscience, F-33076 Bordeaux, France, and ${ }^{6}$ Centre National de la Recherche Scientifique, \\ UMR 5287, Aquitaine Institute for Cognitive and Integrative Neuroscience, F-33076 Bordeaux, France
}

Enhanced motivation to take drugs is a central characteristic of addiction, yet the neural underpinning of this maladaptive behavior is still largely unknown. Here, we report a D1-like dopamine receptor (DRD1)-mediated long-term potentiation of GABA $\mathrm{A}_{\mathrm{APSC}}$ (D1-LTP $_{\mathrm{GABA}}$ ) in the oval bed nucleus of the stria terminalis that was positively correlated with motivation to self-administer cocaine in rats. Likewise, in vivo intra-oval bed nucleus of the stria terminalis DRD1 pharmacological blockade reduced lever pressing for cocaine more effectively in rats showing enhanced motivation toward cocaine. D1-LTP ${ }_{\mathrm{GABA}}$ resulted from enhanced function and expression of G-proteinindependent DRD1 coupled to c-Src tyrosine kinases and required local release of neurotensin. There was no D1-LTP ${ }_{\mathrm{GABA}}$ in rats that self-administered sucrose, in those with limited cocaine self-administration experience, or in those that received cocaine passively (yoked). Therefore, our study reveals a novel neurophysiological mechanism contributing to individual motivation to self-administer cocaine, a critical psychobiological element of compulsive drug use and addiction.

\section{Introduction}

Animal models believed to have a behavioral phenotype with face validity for human drug addiction display specific maladaptive behaviors such as enhanced motivation to take drugs, an inability to refrain from drug seeking, and maintained drug use despite adverse consequences (Deroche-Gamonet et al., 2004; Vanderschuren and Everitt, 2004). These maladaptive behaviors can be investigated in the rat drug self-administration model using a progressive ratio (PR) schedule of drug reinforcement, perseverant drug-seeking measures, and resistance of drug self-administration to aversive suppression, respectively (Deroche-Gamonet et al., 2004; Vanderschuren and Everitt, 2004; Belin et al., 2008). In the PR schedule of reinforcement, for example, enhanced effort is required to receive subsequent drug infusions (Deroche-Gamonet et al., 2004; Vanderschuren and Everitt, 2004; Belin et al., 2008). Despite these advances in experimental models of

Received April 29, 2013; revised May 28, 2013; accepted June 13, 2013.

Author contributions: É.C.D. designed research; M.K., X.M., J.D., R.S., C.P.N., E.R.H., C.D.P., C.C., A.M., A.A.J., É.D., S.C., F.G., and É.C.D. performed research; M.K., X.M., J.D., R.S., E.B., F.G., and É.C.D. analyzed data; E.R.H. and É.C.D. wrote the paper.

This work was supported by the Canadian Institutes of Health (Research Operating Grants \#MOP-79277 and \#MOP-259053 to É.C.D.), The J.P. Bickell Foundation (É.C.D.), and Queen's University (É.C.D.). We thank Dr. Roy Wise (National Institute for Drug Abuse) for providing valuable comments on the manuscript and Thierry Leste-Lasserre and Christine Ryan for technical support.

The authors declare no competing financial interests.

Correspondence should be sent to Éric C. Dumont, Department of Biomedical and Molecular Sciences and Center for Neuroscience Studies, Queen's University, Kingston, Ontario K7L3N6, Canada. E-mail: eric.dumont@queensu.ca. DOI:10.1523/JNEUROSCI.1784-13.2013

Copyright $\odot 2013$ the authors $\quad 0270-6474 / 13 / 3311960-12 \$ 15.00 / 0$ addiction, the underlying neural mechanisms are still largely unknown. Here, we combined behavioral testing of cocaine selfadministration under a PR schedule of reinforcement, brain slice electrophysiology, in situ immunohistochemistry, and in vivo behavioral pharmacology to identify the potential neural mechanism(s) underlying increased motivation to cocaine use in rats.

Recently, we reported a reversal in dopamine (DA) modulation of $\mathrm{GABA}_{\mathrm{A}}$ synaptic transmission that was uniquely associated with prolonged cocaine self-administration and protracted withdrawal (Krawczyk et al., 2011a). We detected DRD1-mediated increase in $\mathrm{GABA}_{\mathrm{A}}$-IPSCs in the oval region of the dorsolateral bed ( $\mathrm{dl}$ ) nucleus of the stria terminalis (ovBNST). The ovBNST is densely innervated by DA-containing axons. Most drugs of abuse trigger robust DA release in this region in vivo and local DRD1 blockade reduces cocaine- and ethanol-mediated reinforcement in rats (Epping-Jordan et al., 1998; Carboni et al., 2000; Eiler et al., 2003). Furthermore, dlBNST blockade of $\mathrm{GABA}_{\mathrm{A}}$ receptors reduces drug reinforcement, which is consistent with our observed DRD1-mediated increase in $\mathrm{GABA}_{\mathrm{A}}$ transmission measured in cocaine-self-administering rats (Hyytiä and Koob, 1995). It is currently unknown whether the BNST contributes in enhanced motivation to seek and take drugs, but functional lesions of the dlBNST area reduce the motivation to struggle and escape in forced-swim tests (Schulz and Canbeyli, 2000; Pezük et al., 2006). In addition, dlBNST deep brain stimulation reduces schedule-induced polydipsia in rats, a rodent model of obsessive-compulsive behaviors that reflects certain aspects of compulsive drug intake involving both DA and 
GABA synaptic transmission (Lopez-Grancha et al., 2008; van Kuyck et al., 2008).

Here, we hypothesized that variation in DRD1-mediated increase in $\mathrm{GABA}_{\mathrm{A}}$-IPSC serves as an important neural correlate for rats' motivation to self-administer cocaine. We report that after a prolonged cocaine self-administration experience, DRD1mediated increase of ovBNST GABA $\mathrm{A}_{\mathrm{A}}$-IPSC was largely irreversible, revealing a long-term potentiation of GABA synapses $\left(\mathrm{D} 1-\mathrm{LTP}_{\mathrm{GABA}}\right)$. D1-LTP $\mathrm{GABA}_{\mathrm{G}}$ amplitude and in vivo response to intra-ovBNST DRD1 blockade was positively linked with individual lever pressing magnitude on the PR schedule. D1$\mathrm{LTP}_{\mathrm{GABA}}$ resulted from de novo expression of postsynaptic DRD1 positively coupled to c-Src tyrosine kinases (TKs) in a G-proteinindependent way and required local neurotensin release. Our results reveal a novel neuromodulatory mechanism for DA that is specific to prolonged cocaine intake and may further encode individual motivation to self-administer cocaine in rats.

\section{Materials and Methods}

Animals. One hundred and twenty male Long-Evans rats (Charles River Laboratories) weighing 250-300 g were included in the study. The rats were maintained on a $12 \mathrm{~h}$ reversed light/dark cycle (9:00 A.M. lights off/9:00 P.M. lights on) with all behavioral testing done during the dark cycle. The rats were allowed to acclimatize for a minimum of $7 \mathrm{~d}$ upon arrival to the facility. Rat chow and water were provided ad libitum in the home cages and in the test chambers for the duration of the experimental sessions. All experiments were conducted in accordance with the Canadian Council on Animal Care guidelines for use of animals in experiments and approved by the Queen's University Animal Care Committee. Eighty-nine rats implanted with indwelling catheters for intravenous cocaine administration were included in the study. Fourteen of these rats also had intracranial guide-cannulas implanted for intra-BNST or intracerebroventricular (ICV) microinjections. Eight rats implanted with intra-BNST guide-cannulas only were also included in the study.

Surgeries. Rats were weighted and anesthetized with isoflurane $(2-3 \%$, $5 \mathrm{~L} / \mathrm{min}$ ). Manufactured indwelling catheters were used for intrajugular cannulations (Model IVSA28' Camcath). The end of the tubing was inserted $32 \mathrm{~mm}$ into the right jugular vein toward the right atria and tied with 4.0 suturing silks. The rest of the tubing was fed subcutaneously to a back-mounted $28 \mathrm{Ga}$ cannula. All incisions were closed with $4-0$ absorbable suturing silk. Upon surgery completion and recovery from anesthesia, rats were returned to the colony room. The rats received Anafen (5 $\mathrm{mg} / \mathrm{kg}$ ) injections subcutaneously, for $3 \mathrm{~d}$ postoperatively and also received fruits to supplement normal chow diet during recovery. IV cannulas were flushed daily with a sterile heparin-saline solution (20 IU heparin/ml) to prevent clots and conserve patency. Rats assigned to intra-ovBNST or ICV pharmacological manipulations were placed in a stereotaxic instrument and secured by nonrupture ear bars under isoflurane anesthesia $(2-3 \%, 5 \mathrm{~L} / \mathrm{min})$. Double guide cannulas (Plastics One) were bilaterally implanted into the oval region of the dorsal BNST $(-0.26$ A.P., \pm 1.9 M.L., -6.5 D.V.) or ICV ( -0.26 A.P., \pm 1.9 M.L., -4.5 D.V.). All stereotaxic coordinates were relative to bregma (Paxinos and Watson, 2005). The head attachment was secured in place via four autoclaved $0.08 \times 0.125$ inch jeweler screws and dental acrylic cement. To protect from pathogens and to ensure patency, the guide cannulas were fitted with an autoclaved $30 \mathrm{Ga}$ stylet and covered with a screw-on cap.

Acquisition of instrumental operant behaviors. Behavioral testing for sucrose or cocaine self-administration was conducted in operant chambers, each equipped with a house light, a response lever with a cue light, and a food dispenser for sucrose pellet reinforcement (Med Associates). Rats were placed in the operant chambers for daily $4 \mathrm{~h}$ sessions. Rats learned sucrose- or cocaine-reinforced operant responding on a fixed ratio-1 (FR-1) schedule where each lever press illuminated the cue light and delivered the reward, either one sucrose pellet $(75 \mathrm{mg}$ ) or a cocaine$\mathrm{HCl}$ infusion $(0.75 \mathrm{mg} / \mathrm{kg}$ in $0.12 \mathrm{ml}$ of sterile saline over $4 \mathrm{~s})$. Upon each reward delivery, the lever was retracted for $20 \mathrm{~s}$, during which the cue light remained illuminated; no additional responses could occur during this holding period. Training was considered acquired when the rats responded 25 times in a titrated fashion (infusions or pellet delivery at regular time intervals) for 3 consecutive days. All rats without health or catheter patency issues acquired cocaine self-administration successfully $(5.1 \pm 0.2 \mathrm{~d}, n=65)$. Rats systematically acquired sucrose selfadministration behavior in $3 \mathrm{~d}$.

Intracranial behavioral pharmacology. Upon reaching criteria for acquisition, rats assigned to maintenance of sucrose or cocaine selfadministration graduated to a PR schedule of reinforcement in which lever pressing to obtain each subsequent reward increased according to the following equation: response ratio $=5 \mathrm{e}^{\text {(injection number } \times 0.2)}-5$ (Richardson and Roberts, 1996). Final ratio pressing was used as the dependent variable in the PR schedule of reinforcement. Final ratio pressing was defined as the last bout of lever pressing required to reach breakpoint (BP). BP is the last reward received within a 60 min time period (Richardson and Roberts, 1996). Therefore, rats received intraBNST microinjections upon reaching stable responding over a period of $3 \mathrm{~d}$ (i.e., when $\log$ final ratio pressing was within $8 \%$ deviation of a $3 \mathrm{~d}$ average). The rats received $0.5 \mu \mathrm{l}$ per side intra-BNST or ICV microinjections of sterile saline $0.9 \%$ (vehicle) or SCH-23390 immediately before the behavioral sessions. All the rats in the intra-ovBNST group included in the study received a total of 4 microinjections: vehicle and 3 doses of SCH-23390 $(0.4,0.8,1.6 \mu \mathrm{g} / \mu \mathrm{l} / \mathrm{side})$. Four (1 sucrose, 3 cocaine) supplementary rats were included Figure $1 d$ to obtain a statistically reliable correlation analysis. These rats may not have received all doses of $\mathrm{SCH}-$ 23390 and had to be removed from the dose-response experiments to satisfy a two-way mixed-model ANOVA (see Statistical analyses section). Rats in the ICV group only received vehicle and the highest dose of $\mathrm{SCH}-23390(1.6 \mu \mathrm{g} / \mu \mathrm{l} / \mathrm{side})$. All microinjections occurred between days 15 and 60 of cocaine or sucrose self-administration on the PR schedule (Fig. 1a). Doses of SCH were chosen according to recent work in the striatum, hippocampus, and amygdala (Andrzejewski et al., 2005; Pezze et al., 2007). Drugs were delivered over a $90 \mathrm{~s}$ interval using a syringe pump (Razel Scientific Instruments). Drugs were blindly assigned following a pseudorandom schedule. The rats were visually monitored and no observable motor impairment or drowsiness was detected. Lever pressing and reward delivery data were acquired with MedPC-IV and analyzed with SoftCR-IV (Med Associates). Cannula placements were verified at the end of the experiments with microinjections of fluorescent microspheres (fluorospheres of carboxylate-modified microspheres, $0.04 \mu \mathrm{m}, 0.5 \mu \mathrm{l}$ per side; Invitrogen) over a $90 \mathrm{~s}$ interval using a syringe pump to verify the absence of ICV leaks in the intra-ovBNST group. The spread of fluorescent microspheres is shown in Figure $1 \mathrm{f}$ as an indication of cannula placement rather than an indication of drug diffusion. To increase bilateral placement accuracy, double-guide cannula mounts and a straight descend approach were used, inevitably traversing the lateral ventricles. Only rats with correct placement and absence of ICV fluorescent beads were included in the study ( $n=10$ cocaine and 8 sucrose).

Experimental groups for electrophysiology. Rats were assigned to 5 experimental groups: Control $(n=14)$, Sucrose $(n=10)$, Cocaine Acquisition $(n=9)$, Cocaine Maintenance $(n=56)$, and Cocaine Yoked $(n=$ 8 ). Rats in the Control group were singly housed and age-matched to behaviorally trained rats. Rats in the Cocaine Acquisition group were killed for recordings $20 \mathrm{~h}$ after reaching criteria for acquisition of cocaine self-administration. Rats assigned to maintenance (Sucrose and Cocaine Maintenance) self-administration graduated to the PR schedule of reinforcement for a period spanning $15-53 \mathrm{~d}$ upon reaching criteria for acquisition and were also killed $20 \mathrm{~h}$ after their last self-administration session. A broad range of numbers of days of the PR schedule was used for the Cocaine Maintenance group to match as closely as possible the cocaine experience of the rats included in the behavioral pharmacology experiments. Cocaine Yoked rats were included in the study to dissociate the neural mechanisms underlying drug-taking behavior from the neural adaptations produced by chronic exposure to cocaine (Krawczyk et al., 2011a, 2011b). Accordingly, Cocaine Yoked rats received cocaine in exactly the same amount and frequency as their self-administering Cocaine Maintenance counterparts. Levers were not available but reward delivery was also signaled by a $20 \mathrm{~s}$ cue light illumination. Cocaine Yoked rats were killed for electrophysiology experiments the day before their Cocaine Main- 
tenance counterparts. One supplementary cocaine self-administration group was added to facilitate the interpretation of the results obtained with the Cocaine Maintenance group. These rats $(n=3)$ remained on the FR-1 schedule of reinforcement for $15 \mathrm{~d}$ after the acquisition phase and were killed for electrophysiological recordings $20 \mathrm{~h}$ after their last self-administration procedure. This group was treated separately in the interest of clarity.

Slices preparation and electrophysiology. The rats were deeply anesthetized with isoflurane (5\% at $5 \mathrm{~L} / \mathrm{min}$ ) and their brains rapidly removed and kept in ice-cold physiological solution containing the following (in $\mathrm{mm}$ ): 126 $\mathrm{NaCl}, 2.5 \mathrm{KCl}, 1.2 \mathrm{MgCl}_{2}, 6 \mathrm{CaCl}_{2}, 1.2$ $\mathrm{NaH}_{2} \mathrm{PO}_{4}, 25 \mathrm{NaHCO}_{3}$, and 12.5 D-glucose equilibrated with $95 \% \mathrm{O}_{2} / 5 \% \mathrm{CO}_{2}$. The brains were cut into coronal slices $(250 \mu \mathrm{m})$ with a vibrating microtome (VT-1000; Leica) in the physiological solution maintained at $2^{\circ} \mathrm{C}$ throughout the slicing procedure. Slices containing the BNST were incubated at $34^{\circ} \mathrm{C}$ for at least $60 \mathrm{~min}$ and transferred to a chamber that was constantly perfused $(3 \mathrm{ml} / \mathrm{min})$ with the physiological solution maintained at $34^{\circ} \mathrm{C}$. Whole-cell voltage-clamp recordings were made using glass microelectrodes (3.5 $\mathrm{M} \Omega$ ) filled with a solution containing the following (in mM): $70 \mathrm{~K}^{+}$-gluconate, $80 \mathrm{KCl}, 1$ EGTA, 5 HEPES, 2 MgATP, 0.3 GTP, and 1 P-creatine. $E_{\mathrm{Cl}}$ in these conditions was $\sim-32 \mathrm{mV}$ such that evoked $\mathrm{GABA}_{\mathrm{A}}$ postsynaptic responses were inward currents when neurons were voltage clamped at $-70 \mathrm{mV}$. Detailed methodology for recordings of ovBNST $\mathrm{GABA}_{\mathrm{A}}$-IPSC was described previously (Krawczyk et al.,

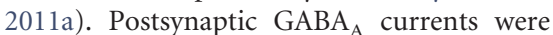
evoked by local fiber stimulation with tungsten bipolar electrodes in the presence of the AMPA antagonist DNQX $(50 \mu \mathrm{M})$. There was no measurable NMDA-EPSC in these conditions. Electrodes were placed in the ovBNST 100-500 $\mu \mathrm{m}$ dorsal from the recorded neurons and paired electrical stimuli $(10-100 \mu \mathrm{A}, 0.1 \mathrm{~ms}$ duration, $20 \mathrm{~Hz}$ ) were evoked at $0.1 \mathrm{~Hz}$. All drugs were bath applied through the perfusion system or, in many cases, included in the internal solution. Recordings were made using a Multiclamp 700B amplifier and a Digidata 1440A (Molecular Devices). Data were acquired and analyzed with Axograph X running on Apple computers.

Immunohistochemical detection of DRD1. Seven rats (3 Control, 4 Cocaine Maintenance) were deeply anesthetized with sodium chloral hydrate (400 mg/kg, i.p.) and perfused transcardiacally with 50-100 ml of $0.9 \% \mathrm{NaCl}$ followed by $300 \mathrm{ml}$ of fixative consisting of $2 \%$ PFA with $0.2 \%$ glutaraldehyde in $0.1 \mathrm{M} \mathrm{PB}, \mathrm{pH}$ 7.4. Brains were quickly removed, left overnight in $2 \%$ PFA at $4^{\circ} \mathrm{C}$, and cut into $60-\mu \mathrm{m}$-thick coronal slices with a vibrating blade microtome (VT1000S; Leica). To enhance the penetration of the immunoreagents, the sections were equilibrated in a cryoprotectant solution ( $0.05 \mathrm{M} \mathrm{PB}, \mathrm{pH} 7.4$, containing $25 \%$ sucrose and $10 \%$ glycerol), freeze-thawed, and stored in PBS with $0.03 \%$ sodium azide until needed. DRD1 was detected by immunohistochemistry according to previously described and validated procedures (Berthet et al., 2009) using a monoclonal antibody raised in rat against a 97 aa sequence corresponding to the $\mathrm{C}$ terminus of the human DRD1 (SigmaAldrich). Brain slices containing the ovBNST were incubated in 4\% NGS

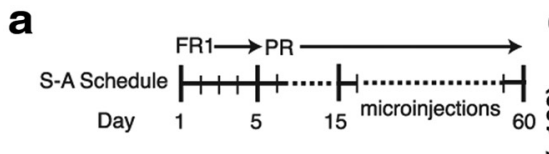

c
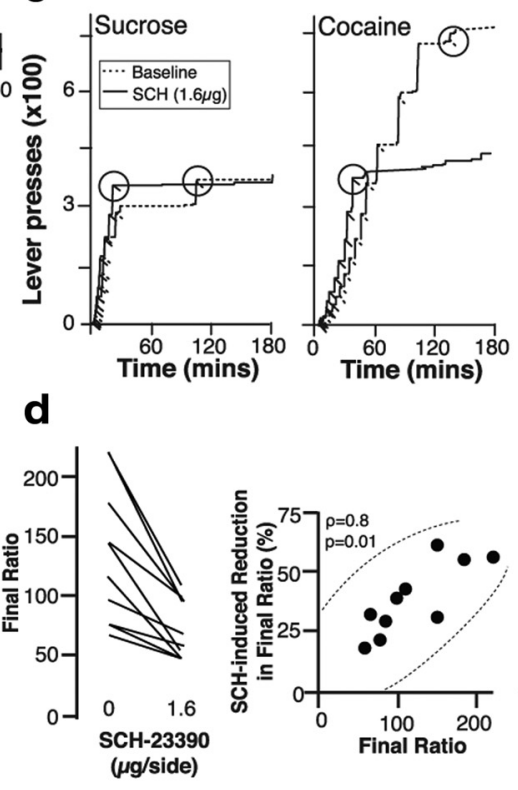

e

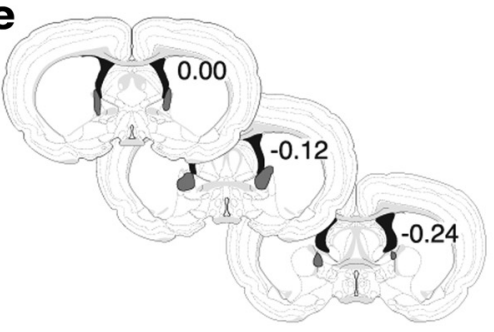

$\mathbf{f}$
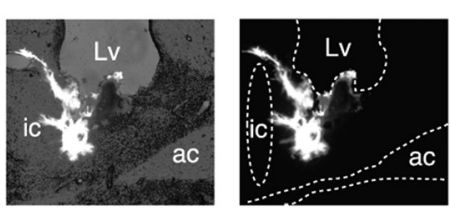

Figure 1. Effect of intra-ovBNST DRD1 blockade on sucrose and cocaine self-administration. $\boldsymbol{a}$, Schedule for oral sucrose or intravenous cocaine self-administration $(0.75 \mathrm{mg} / \mathrm{ml} /$ injection). S-A, self-administration. $\boldsymbol{b}$, Effect of intra-ovBNST or ICV microinjections of the DRD1 antagonist SCH-23390 on sucrose or cocaine self-administration on final ratio pressing (top), time to reach $p<0.05$. c, Representative experiments showing the effect of intra-ovBNST SCH-23390 (1.6 $\mu \mathrm{g} / \mathrm{side}$, solid lines) compared with baseline (dotted lines) on sucrose (left) and cocaine (right) self-administration. Oblique tick marks indicate reward deliveries. BPs compared with vehicle on final ratio pressing for cocaine in each rat tested. Right: Correlation between SCH (1.6 $\mu \mathrm{g} / \mathrm{side}$ )-induced reduction in final ratio pressing and magnitude of final ratio pressing for cocaine. Each dot represents data from one rat. Dotted placements from which data were used in $\boldsymbol{b}$. $\boldsymbol{f}$, Representative histological location of a typical microinjection of fluorescent microspheres seen in bright- or dark-field microscopy. Schematics of coronal brain sections are adapted from Paxinos and Watson (2005). Lv, lateral ventricles; ac, anterior commissure; ic, internal capsule.

or in normal donkey serum in PBS for $1 \mathrm{~h}$ at room temperature (RT) and then in the DRD1 antibody (1:1000) supplemented with $1 \%$ NGS or normal donkey serum overnight at RT. After washing $(3 \times 10 \mathrm{~min})$ in PBS, the sections were incubated in goat anti-rat IgG coupled to biotin (1:200 in PBS for $1.5 \mathrm{~h}$; GE Healthcare). After three rinses $(3 \times 10 \mathrm{~min})$ in PBS, the sections were then incubated in avidin-biotin complex (1: 200, Vector ABC Elite; Vector Laboratories) in PBS for $1.5 \mathrm{~h}$ at RT and again rinsed $(3 \times 10 \mathrm{~min})$ in PBS. The immunoreactive sites were revealed by a combination of the glucose oxidase DAB $(0.05 \%$ in Trizma buffer; Sigma-Aldrich) method and the DAB-nickel method. The reaction was stopped by several washes in $\mathrm{H}_{2} \mathrm{O}$. The sections were mounted on glass slides, dehydrated, and mounted in Eukitt (Electron Microscopy Sciences). Negative immunohistological control demonstrated the 
absence of signal when omitting the primary antibody. The number of DRD1-immunopositive neurons in ovBNST was analyzed from immunoperoxidase-treated sections using an image analysis system (Mercator version 2.10, Explora Nova). At least three sections per rat were analyzed by an examiner blinded to experimental conditions. Densitometric analysis of perimembrane area of 100 DRD1-positives neurons was performed using the same image analysis system in the whole ovBNST. This measure was exclusively performed in neuron sections where the nucleus was clearly distinguishable.

$D 1 R$ qPCR. RNA extracts from isolated ovBNST were purified with RNeasy Plus Micro Kit (QIAGEN), samples were treated with DNase (RNase-Free DNase Set; QIAGEN). The quality and quantity of the RNA samples were tested on a Model 2100 bioanalyzer with the RNA 6000 Pico LabChip Kit (Agilent Technologies). Quality was evaluated using the RNA Integrity Number value introduced by Agilent Technologies. A total of $3.5 \mathrm{ng}$ of RNA was retrotranscribed to $\mathrm{CDNA}$ at $50^{\circ} \mathrm{C}$ with reverse transcriptase (Fermentas) in the presence of $1 \mu \mathrm{l}$ of random primer (150 $\mathrm{ng} / \mu \mathrm{l})$ and $0.5 \mu \mathrm{l}$ of oligodt $(200 \mathrm{ng} / \mu \mathrm{l})$. Real-time PCR was performed on a Light Cycler 480 (Roche) in a total volume of $10 \mu$ l using $0.2 \mathrm{ng}$ cDNA as templates, $3 \mu \mathrm{l}$ mixed forward and reverse primers (D1R: forward CGCGTAGACTCTGAGATTCTGAATT, reverse GAGTTAAGGA GCCACCACATCAGT), and $5 \mu$ of mixture $2 \mathrm{X}$ Roche containing Fast Start TaqDNA polymerase reaction buffer dNTP mix (with dUTP instead of dTTP), Sybr Green I dye, and $\mathrm{MgCl}_{2}$. Relative expression of each gene was normalized respect to two different endogenous housekeeping control genes (Gapdh and Sdha; Gapdh: forward GAATGGGAAGCTGG TCATCAAC, reverse CCATTTGATGTTAGCGGGATCT; Sdha: forward TGCGGAAGCACGGAAGGAGT, reverse CTTCTGCTGGCCCT CGATGG) determined using the algorithm Genorm. The PCR data were exported in Gene Expression Analysis Software Environment (Inserm U862) for further analysis. The cycle point value of D1R was normalized against that of Sdha and Gapdh, and the relative level of expression was calculated using the comparative $2-\Delta \Delta$ Ct method.

Drugs. Stock solutions of DA (10 mM), quinpirole (1 mM), neurotensin (1 mM), and SCH-23390 (10 mM) were prepared in double-distilled water. Stock solution of DNQX (100 mM), SKF-81297 (1 mM), sulpiride (1 $\mathrm{mm}), \mathrm{U}-73122$ (10 mM), GTP- $\beta$-s (10 mM), H89 (10 mM), PP2 (10 mM), PP3 (10 mM), genistein $(10 \mathrm{~mm})$, daidzein $(10 \mathrm{~mm})$, and SR 14298 (10 $\mathrm{mM}$ ) were prepared in DMSO (100\%). All drugs were further dissolved in the physiological solutions at the desired concentrations and the final DMSO concentration never exceeded $0.1 \%$. Cocaine- $\mathrm{HCl}$ was dissolved at $2.5 \mathrm{mg} / \mathrm{ml}$ in sterile saline $0.9 \%$ and the $\mathrm{pH}$ was adjusted to 7.3 with $\mathrm{NaOH}(1 \mathrm{~N})$. For microinjection experiments, $\mathrm{SCH}-23390$ was dissolved in sterile saline $0.9 \%$ at $0.8,1.6$, and $3.2 \mu \mathrm{g} / \mu \mathrm{l}$. Drugs were obtained from Sigma-Aldrich or Tocris Biosciences except cocaine- $\mathrm{HCl}$, which was obtained from Medisca.

Statistical analyses. Drug-induced changes in postsynaptic current peak amplitude were measured from baseline and are shown as percentages as follows: (Peak amplitude drug - Peak amplitude $_{\text {baseline }} /$ Peak amplitude $_{\text {baseline }}{ }^{*} 100$. Data are reported as means \pm SEM. In graphs where time courses of drug effects are presented, each data point is the

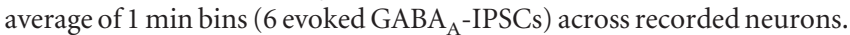
Therefore, data points are repeated measures but are still represented as means \pm SEM. In such cases, SEM is presented to provide a visual indication of the variability across neurons, but no statistical conclusions were made from this variability measure. Paired-pulse ratios (PPRs) were calculated by dividing the second (S2) by the first (S1) peak amplitude. PPRs were compared before and after drug application using paired $t$ tests. Peak amplitudes for S1 and S2 were calculated from a baseline value measured immediately before the stimulus artifacts; in cases where $\mathrm{S} 1$ did not fully decay, the baseline for S2 differed from that of S1 (for in-depth discussion of this issue, see Krawczyk et al., 2011a, 2011b). The coefficient of variation $(\mathrm{CV})$ by plotting $r\left[\left(\mathrm{CV}_{\text {baseline }}^{2}\right) /\left(\mathrm{CV}_{\mathrm{DRD1}}^{2}\right)\right]$ against $\pi$ (Peak amplitude ${ }_{\mathrm{DRD}} /$ Peak amplitude baseline ) and computed bivariate linear fits of $r$ by $\pi$ (Faber and Korn, 1991). ANOVAs were used to compare multiple means and the appropriate statistical tests for multiple comparisons conducted when ANOVAs deemed significance. All statistics from the within-subjects ANOVAs were reported using the Greenhouse-Guesser correction for violations in sphericity, and degrees of freedom for Greenhouse-Giesser values are rounded up to the nearest whole number. Followup analysis for interactions on the betweensubjects variables were evaluated with simple main effect analyses and independent samples pairwise $t$ tests. To control for type I error rates across multiple comparisons, a Bonferroni correction was applied to all $p$-values unless otherwise stated. All statistical analyses were done with JMP 10.0 (SAS Institute).

\section{Results}

OvBNST DRD1 signaling is positively linked with motivation to self-administer cocaine

We previously reported a switch from DRD2- to DRD1mediated modulation of $\mathrm{GABA}_{\mathrm{A}}$-IPSC in ovBNST neurons of cocaine-self-administering rats (Krawczyk et al., 2011a). To determine the behavioral significance of this alteration in DA receptor signaling, we tested the hypothesis here that intra-ovBNST DRD1 blockade would be more effective in subjects reaching higher BPs on the PR schedule of reinforcement for cocaine. We also measured the effects of intra-ovBNST DRD1 pharmacological blockade on sucrose self-administration and hypothesized that the DRD1 antagonist SCH-23390 would be mostly ineffective because there is no measurable DRD1-mediated increase in $\mathrm{GABA}_{\mathrm{A}}$-IPSC in these rats (Krawczyk et al., 2011a).

Bilateral intra-ovBNST microinjections of SCH-23390 (0.4, 0.8 , and $1.6 \mu \mathrm{g} / \mathrm{side}$ ) interfered with cocaine, but not sucrose, self-administration on a PR schedule of reinforcement (Fig. 1b, top; Fig. $1 c$; Group $\times$ Dose of SCH interaction: $F_{(3,11)}=3.1, p=$ $0.001)$. SCH-23390 also dose-dependently reduced time to reach $\mathrm{BP}$ in cocaine self-administering rats (Fig. $1 b$, middle; Group $\times$ Dose of SCH interaction: $\left.F_{(3,11)}=1.81, p=0.008\right)$. Bilateral ICV microinjections of SCH-23390 (1.6 $\mu \mathrm{g} /$ side $)$ were ineffective at interfering with cocaine self-administration (Fig. $1 b$; final ratio pressing, $t_{3}=0.1, p=0.1$; time to reach $\mathrm{BP}, t_{3}=0.7, p=0.5$ ). SCH-23390 also dose-dependently increased the rate of lever pressing in the reward-rich portion of cocaine (time to reach $1 / 2$ $\mathrm{BP}$ in minutes), but not sucrose self-administration (Fig. $1 b$, bottom; Group $\times$ Dose of SCH interaction: $\left.F_{(3,11)}=1.2, p=0.03\right)$. This shows that SCH-23390 most likely reduced BP on the PR schedule by reducing the reinforcing property of cocaine (as shown previously shown by Epping-Jordan et al., 1998) and not through motor impairment or precipitated fatigue. SCH-23390 $1.6 \mu \mathrm{g} /$ side did not affect the time to reach $1 / 2 \mathrm{BP}$ when given ICV (Fig. $1 b$, bottom right; $t_{3}=0.8, p=0.5$ ). SCH-23390 at the highest tested concentration $(1.6 \mu \mathrm{g})$ was more potent at reducing lever pressing in rats reaching higher BP, suggesting that the DRD1 in the dIBNST may contribute to the exaggerated motivation to self-administer cocaine that certain individuals displayed on the PR schedule (Fig. 1d). Therefore, SCH-23390-induced reduction in lever pressing for cocaine was positively correlated with $\mathrm{BP}$ magnitude that individual rats reached on the PR schedule of reinforcement (Fig. $1 d$; Spearman's $\rho=0.8, p=0.01$ ).

\section{Prolonged cocaine self-administration experience reveals DRD1-mediated LTP of ovBNST GABA synapses}

We next determined whether in vivo pharmacological blockade of ovBNST DRD1 is related to the in vitro D1-mediated increase in $\mathrm{GABA}_{\mathrm{A}}$-IPSC we measured previously in rats with a cocaine self-administration experience (Krawczyk et al., 2011a). We further sought to determine whether DRD1-mediated increase in $\mathrm{GABA}_{\mathrm{A}}$-IPSC was specific to prolonged cocaine self-administration by comparing this response in brain slices prepared from five groups of rats: (1) age-matched and naive to any behavioral procedures or drug exposure (Control), (2) with a prolonged 
(20-30 d) sucrose self-administration experience on the PR schedule of reinforcement (Sucrose), (3) trained to acquire operant responding for cocaine on an FR-1 schedule of reinforcement (Cocaine Acquisition), (4) with a prolonged (15-53 d) cocaine self-administration experience (Cocaine Maintenance), or (5) yoked to Cocaine Maintenance rats that received cocaine in exactly the same amounts and frequency (Cocaine Yoked) (Fig. $2 a$ and see Materials and Methods for in-depth description and justification of experimental groups). Twenty hours after the last self-administration session, we prepared brain slices for wholecell voltage-clamp recordings to measure the effect of DRD1 activation on ovBNST GABA $A_{A}$-IPSC. We activated DRD1 by briefly (5 min) bath applying the DRD1-like agonist SKF-81297 (1 $\mu \mathrm{M})$ or coapplying DA $(1 \mu \mathrm{M})$ and the DRD2 antagonist sulpiride (10 $\mu \mathrm{M})$ and measured the change in amplitude of electrically evoked $\mathrm{GABA}_{\mathrm{A}}$-IPSC (Fig. 2).

SKF (Fig. 2c) or the combination of DA and sulpiride (Fig. 2d) had little effect on $\mathrm{GABA}_{\mathrm{A}}$-IPSC amplitude in ovBNST neurons of Control, Sucrose, Cocaine Acquisition, or Cocaine Yoked rats, confirming the virtual absence of functional ovBNST DRD1 in these conditions (also see Krawczyk et al., 2011a, 2011b). In contrast, both $\operatorname{SKF}\left(+125.4 \pm 22.5 \%\right.$, Fig. $2 c$; Time $\times$ Group interaction, $F_{(12,47)}=$ 8.12, $p<0.0001)$ and DA/sulpiride $(+98.5 \pm 10.8 \%$, Fig. $2 b, d$; Time $\times$ Group interaction, $\left.F_{(12,52)}=3.9, p=0.0003\right)$ produced a long-lasting increase in $\mathrm{GABA}_{\mathrm{A}}$-IPSC amplitude in Cocaine Maintenance rats. DA $(1 \mu \mathrm{M})$ also produced a sustained increase of $\mathrm{GABA}_{\mathrm{A}}$-IPSC in Cocaine Maintenance, but not in Cocaine Yoked rats, in the absence of DRD2 blockade, but this was of smaller amplitude (+23.1 \pm 5.06\%; Krawczyk et al., 2011a). This shows that DRD2 blockade was not necessary to measure a sustained increase in $\mathrm{GABA}_{\mathrm{A}}$-IPSC but rather experimentally amplified the response, facilitating the investigation of the underlying mechanisms. SKF also produced a long-lasting increase in $\mathrm{GABA}_{\mathrm{A}}$-IPSC amplitude $(+134.5 \pm 7.1 \%, n=8$ neurons in 3 rats $)$ in a group of rats that, in contrast to the Cocaine Maintenance group, remained on the reward-rich schedule (FR-1) for $15 \mathrm{~d}$ after the acquisition phase. This confirms our previous observation that the switch from D2DR to D1DR control of GABA transmission in the ovBNST of cocaineself-administering rats is not due to the transition from a rewardrich to reward-lean schedule (Krawczyk et al., 2011a).

The increase in $\mathrm{GABA}_{\mathrm{A}}$-IPSC amplitude largely outlasted washing SKF or DA out of the bath and, accordingly, we refer to this response as DRD1-dependent LTP of GABA ${ }_{\mathrm{A}}$-IPSC (D1$\left.\mathrm{LTP}_{\mathrm{GABA}}\right)$. In some neurons where extended high-quality wholecell recordings were obtained, D1- $\mathrm{LTP}_{\mathrm{GABA}}$ was still sustained for tens of minutes (Fig. $2 e$ shows the data from 2 neurons with a 55 min postwash period). Preapplication of the DRD1 competitive antagonist SCH-23390 (10 $\mu \mathrm{M})$ completely prevented D1$\mathrm{LTP}_{\mathrm{GABA}}$, confirming that DA acted through D1-like DA receptors (Fig. 2e, right). Conversely, applying SCH-23390 at the

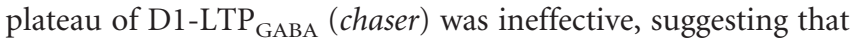
transient DRD1 activation was sufficient to trigger self-sustaining mechanisms supporting $\mathrm{LTP}_{\mathrm{GABA}}$ (Fig. $2 e$, middle; main effect of SCH-23390 on D1-LTP ${ }_{\mathrm{GABA}}$ at time $25-30 \mathrm{~min} ; F_{(2,26)}=13.1$, $p=0.0001$; Dunnett's method revealed a significant effect of preapplication of SCH-23390 [ $p=0.0004]$ but not of SCHchaser $[p=0.6])$.

D1-LTP $\mathrm{GABA}_{\text {was }}$ accompanied by a significant reduction (SKF; $t_{9}=-4.7, p=0.001, \mathrm{DA} /$ sulpiride; $t_{12}=-6.4, p<$ $0.0001)$ in PPR ( $\left.\mathrm{PPR}_{50 \mathrm{~ms}}\right)$, suggesting an increase in the presynaptic probability of GABA release (Fig. $2 b, f ;$ Zucker, 1989). CV analysis, taken as an index of neurotransmitter release fidelity as a function of change in response amplitude, confirmed that the

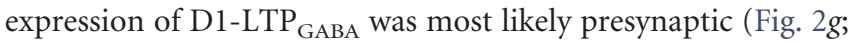
Spearman's $\rho=0.7, p=0.0003$; Faber and Korn, 1991). Therefore, interevent amplitude variability decreased monotonically with DRD1-induced enhancement in $\mathrm{GABA}_{\mathrm{A}}$-IPSC amplitude, indicative of facilitation in presynaptic GABA release (Faber and Korn, 1991; Krawczyk et al., 2011a, 2011b). Presynaptic expression of D1-LTP $\mathrm{GABA}_{\mathrm{G}}$ is thus consistent with activity-dependent $\mathrm{LTP}_{\mathrm{GABA}}$ in other brain regions, a mechanism that involves enhanced probability of GABA release yet requires postsynaptic release of a retrograde messenger (e.g., nitric oxide; Nugent et al., 2008).

Because intra-ovBNST SCH-23390-induced reduction in lever pressing for cocaine was positively correlated with BP magnitude that individual rats reached on the PR schedule of reinforcement (Fig. 1d,e), we hypothesized that the amplitude of D1-LTP $\mathrm{GABA}_{\mathrm{GA}}$ may also positively correspond to the rat's motivation to self-administer cocaine. Indeed, the magnitude of DRD1mediated increase in $\mathrm{GABA}_{\mathrm{A}}$-IPSC was positively related with $\mathrm{BP}$ on the PR schedule of cocaine reinforcement (Fig. $2 h$; Spearman's $\rho=0.7, p=0.01$ ), supporting a putative mechanism underlying individual motivation to self-administer cocaine in rats. In contrast, the increase in $\mathrm{GABA}_{\mathrm{A}}$-IPSC amplitude was not related to the number of days rats spent on the PR schedule (Fig. 2i; Spearman's $\rho=0.2, p=0.64$ ). The data reveal a novel neural mechanism that may underlie the exaggerated motivation to self-administer cocaine certain rats display on the PR schedule of reinforcement. Therefore, we investigated further the cellular and molecular mechanisms responsible for the DRD1-mediated enhancement of ovBNST $\mathrm{GABA}_{\mathrm{A}}$-IPSC. Given the clear lack of DRD1 activity in Sucrose, Cocaine Acquisition, and Cocaine Yoked rats, we narrowed the comparison to Control versus Cocaine Maintenance rats for the remainder of the study.

\section{Prolonged cocaine self-administration experience enhanced ovBNST DRD1 expression}

The ovBNST of Control rats is very low in DRD1, both anatomically (Fig. 3a,b,e,f) and functionally (Fig. 2; Krawczyk et al., 2011a, 2011b). We thus hypothesized that cocaine selfadministration was accompanied by increased expression of DRD1, a phenomenon observed in the striatum of parkinsonian rats or macaque monkeys exposed to chronic DA replacement therapy and in macaque monkeys with a prolonged but not limited cocaine self-administration experience, three well characterized hyperdopaminergic conditions (Nader et al., 2002; Guigoni et al., 2007; Berthet et al., 2009). We detected DRD1 by immunohistochemistry using a monoclonal antibody raised in the rat against a 97 aa sequence corresponding to the $C$ terminus of the human DRD1 (Sigma-Aldrich; Levey et al., 1993). We confirmed a very low level of DRD1 in the ovBNST of Control rats (Fig. $3 a, b)$. In contrast, DRD1 were easily detectable in perikarya and proximal dendrites of ovBNST neurons of Cocaine Maintenance rats (Fig. 3d). The DRD1 cellular distribution was qualitatively and quantitatively modified by the cocaine self-administration with a robust increase in the number of DRD1-expressing neurons (Fig. $3 e ; t_{5}=2.4, p=0.003$ ) and in the perimembranous DRD1 optical density of those ovBNST neurons (Fig. $3 f ; t_{6}=4.1$, $p<0.0001)$. This result suggests active accumulation and anchoring of the DRD1 nearby or at the plasma membrane in cocaine-self-administering rats. The lack of transcriptomic changes affecting DRD1 (qPCR fold change in D1 mRNA between Control: $1.08 \pm 0.08$ vs Cocaine Maintenance: $0.95 \pm 0.09$, $p=0.37)$ is consistent with the acute transcriptomic effects of hyperdopaminergia where proteins can accumulate over time 
a

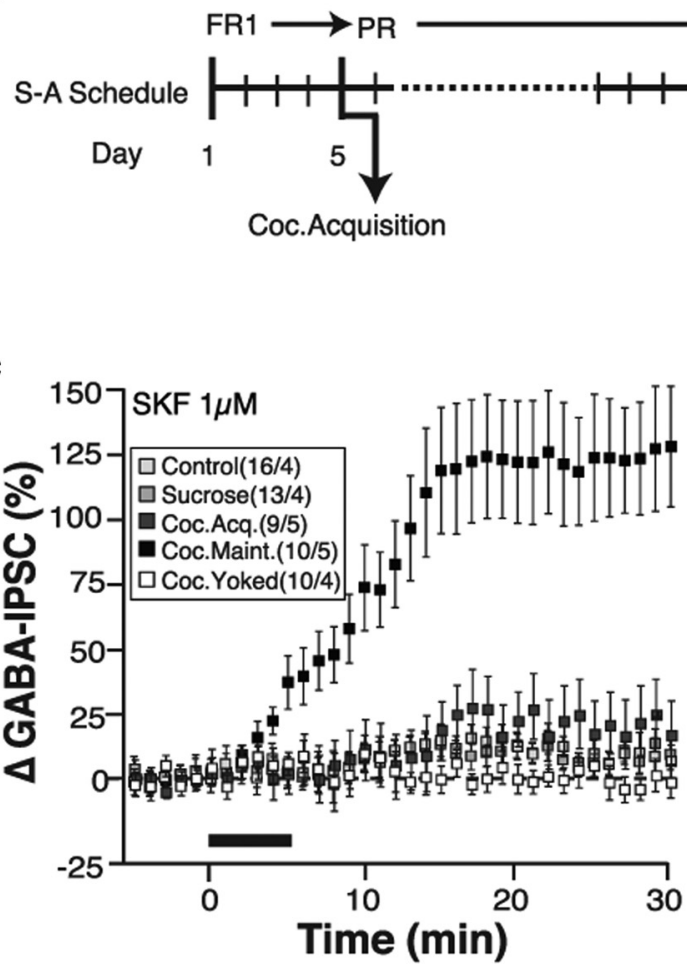

e

- DA+Sulpi $\times$ DA+Sulpi+SCHchaser $\triangle \mathrm{DA}+\mathrm{Sulpi}+\mathrm{SCH}$

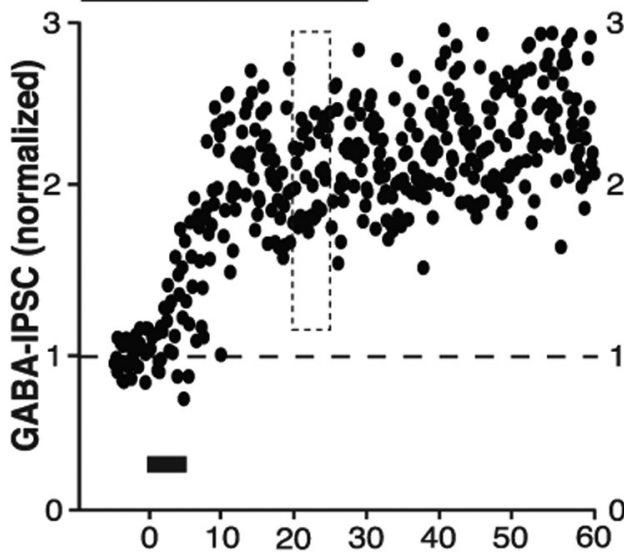

b

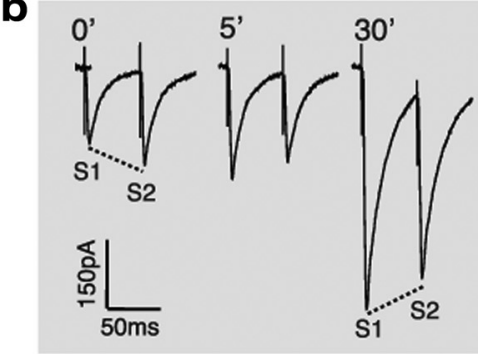

d

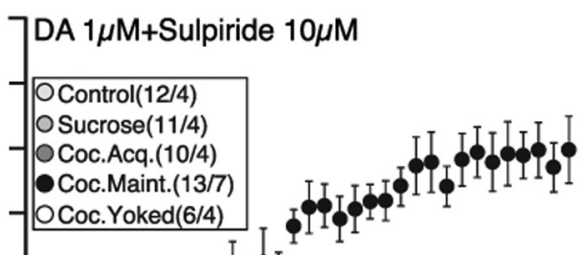

$15-53$

Sucrose

Coc.Maintenance

Coc.Yoked

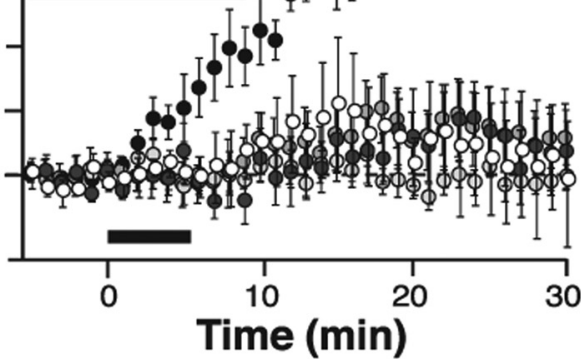


(Aubert et al., 2005; Berthet et al., 2009). The data of Figure 3 suggest that D1-LTP ${ }_{\mathrm{GABA}}$ resulted from enhanced expression of functional DRD1 in the ovBNST occurring with prolonged selfadministration of cocaine that seem, however, to be located in the postsynaptic compartment. Although enhanced DRD1 immunohistochemical product is consistent with the robust D1-LTP $\mathrm{GABA}_{\mathrm{GA}}$, the postsynaptic location seems inconsistent with the presynaptic locus of expression for D1-LTP $\mathrm{GABA}_{\mathrm{G}}$, which is presynaptic (Fig. $2 f, g)$. Therefore, we hypothesized the involvement of an extracellular signaling molecule(s) linking postsynaptic functional DRD1 with presynaptic enhancement of GABA release.

\section{Local neurotensin release links postsynaptic DRD1 with presynaptic LTP $_{\text {GABA }}$}

The ovBNST is exclusively populated with GABA neurons that colocalize corticotropin releasing factor (CRF), neurotensin, or enkephalin, which we predicted could all be released locally in response to DRD1 activation and modulate synaptic transmission (Day et al., 1999). CRF increases GABA $_{\mathrm{A}}$-IPSC amplitude in the dlBNST, albeit through a postsynaptic mechanism, dampen-

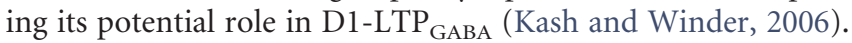
Furthermore, opioid receptor activation reduces GABA transmission in the BNST (Dumont and Williams, 2004; Li et al., 2012). In contrast, neurotensin triggers GABA release in several brain regions, including the rodent prefrontal cortex, striatum, globus pallidus, and hippocampus (Fuxe et al., 1992; O'Connor et al., 1992; Rakovska et al., 1998; Petrie et al., 2005). Here, bath application of neurotensin $(1 \mu \mathrm{M})$ transiently enhanced $\mathrm{GABA}_{\mathrm{A}}$ IPSC amplitude in ovBNST neurons with equal effectiveness in slices from Control and Cocaine Maintenance rats (Fig. $4 a$, main effect of time [Control], $F_{(2,7)}=8.6, p=0.01$; main effect of time

\section{$\leftarrow$}

(Figure legend continued.) horizontal bar) on the amplitude of electrically evoked ovBNST $\mathrm{GABA}_{\mathrm{A}}-\mathrm{IPSC}(0.1 \mathrm{~Hz})$ as a function of time in 5 experimental groups of rats. Evoked events were binned ( 1 min, 6 events) and data points and error bars represent means \pm SEM across all recorded neurons within each experimental group. Numbers in parentheses indicate sample size (neurons/rats). $\boldsymbol{d}$, Effect of a 5 min bath application of DA ( $1 \mu \mathrm{m}$; black horizontal bar) in the presence of sulpiride $(10 \mu \mathrm{M})$ on the amplitude of electrically evoked ovBNST GABA $A_{A}$ IPSC (0.1 $\mathrm{Hz}$ ) as a function of time in 5 experimental groups of rats. $\boldsymbol{e}$, Effect of DRD1 activation with $\mathrm{DA} /$ sulpiride (black horizontal bar) on the amplitude of electrically evoked GABA $\mathrm{A}_{\mathrm{A}}$ IPSC as a function of time in ovBNST neurons of Cocaine Maintenance rats in the presence of the DRD1 antagonist SCH-23390 (10 $\mu \mathrm{m})$ applied throughout (right, gray bar) the recordings or at the peak (middle, hatched bar) of the DRD1-mediated response. Each data point represents the amplitude of one electrically evoked $(0.1 \mathrm{~Hz}) G_{A B A_{A}}-$ IPSC. Inset: Bar chart summarizing the effects of bath application of the DRD1 antagonist SCH-23390 on DRD1-mediated increase in GABA IPSC amplitude calculated at time 20-25 min (averages of 30 events). $\boldsymbol{f}$, Summary of PPR calculated before $\left(0^{\prime}\right)$ and $25 \mathrm{~min}\left(30^{\prime}\right)$ after DRD1 activation in ovBNST neurons of Cocaine Maintenance rats. Each dot represents individual neurons and white symbols are means \pm SEM of PPRs at times 0 and $30^{\prime} . \boldsymbol{g}, \mathrm{CV}$ analysis of the effects of DRD1 activation on the amplitude of evoked GABA $A_{A}$-IPSC in ovBNST neurons from Cocaine rats. Each symbol (SKF, squares; DA, circles) represents the data from one neuron ( $n=23$, combined recordings reported in $\boldsymbol{c}$ and $\boldsymbol{d}$ ). Baseline data were calculated from 30 events preceding DRD1 activation (time -5 to 0 ) and DRD1 data from at time 25-30 min. Dot plot shows an index of the between evoked GABA $A_{A}$ IPSC variability, $r=\left[\left(\left(V_{\text {baseline }}^{2}\right) /\left(C V_{D R D 1}^{2}\right)\right]\right.$ as a function of DRD1-induced change in $\mathrm{GABA}_{\mathrm{A}}-\mathrm{IPSC}$ amplitude, $\Pi=$ Peak amplitude $_{\mathrm{DRD} 1} /$ Peak amplitude $_{\text {baseline. }}$. A positive linear relationship shows a reduction in between evoked $G_{A B A_{A}}$-IPSC variability with increased amplitude, suggesting enhanced efficacy in neurotransmitter release, indicative of a presynaptic effect. $\boldsymbol{h}$, DRD1-induced change in GABA $A_{A}$-IPSC amplitude (time $25-30 \mathrm{~min}$ ) as a function of final ratio pressing for cocaine. Each symbol (SKF, squares; DA, circles) represents the average of all neurons from a single rat $(n=12$, same dataset as in Fig. $2 c, d)$. Dotted lines indicate $95 \%$ confidence interval. $\boldsymbol{i}$, DRD1-induced change in $\mathrm{GABA}_{\mathrm{A}}$-IPSC amplitude (time 25-30 min) as a function of the number of days that individual rats spent on the PR schedule of cocaine reinforcement. Each symbol (SKF, squares; DA, circles) represents the average of all neurons from a single rat ( $n=12$, same dataset as in Fig. $2 c, d$ ). Dotted lines indicate $95 \%$ confidence interval.
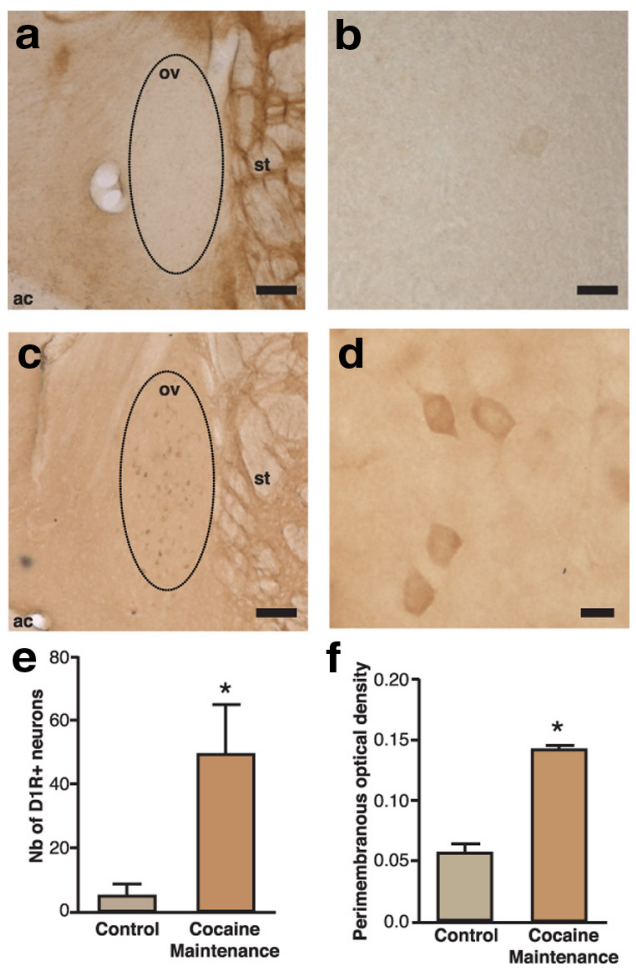

Figure 3. Effect of cocaine self-administration on ovBNST DRD1 expression. Immunohistochemical detection of DRD1 in the ovBNST of Control $(\boldsymbol{a}, \boldsymbol{b})$ and Cocaine Maintenance rats $(\boldsymbol{c}, \boldsymbol{d})$. The representative weak DRD1 signal in ovBNST soma of Control rats $(\boldsymbol{b})$ becomes intense in both the soma and proximal dendrites of ovBNST neurons from a Cocaine Maintenance rat (d). Scale bars in $\boldsymbol{a}, \boldsymbol{c}, 100 \mu \mathrm{m} ; \boldsymbol{b}, \boldsymbol{d}, 10 \mu \mathrm{m} . \boldsymbol{e}$, Number of ovBNST DRD1-positive neurons in Control ( $n=5$ ) or Cocaine Maintenance $(n=6)$ rats. $f$, Perimembranous ovBNST neuron optical density measurement of the DRD1 immunostaining in the same groups. Results represent the means \pm SEM. Asterisks indicate significant difference compared with controls, $p<0.05$. ov, ovBNST; ac, anterior commissure; st, striatum.

[Cocaine], $F_{(2,4)}=8.4, p=0.04 ;$ Time $\times$ Group, $F_{(4,19)}=2.6, p=$ 0.08). In Cocaine Maintenance rats, the effect of neurotensin was presynaptic because the $\mathrm{PPR}_{50 \mathrm{~ms}}$ decreased significantly (Fig. $\left.4 b, c ; t_{11}=-4.1, p=0.001\right)$, supporting its putative role in D1$\mathrm{LTP}_{\mathrm{GABA}}$. To verify that DRD1 activation may cause local neurotensin release, we sought to determine whether postsynaptic depolarization could trigger a neurotensin-dependent increase in $\mathrm{GABA}_{\mathrm{A}}$-IPSC. Repetitive depolarization (from -70 to $0 \mathrm{mV}$ for $100 \mathrm{~ms}$ at $2 \mathrm{~Hz}$ for $5 \mathrm{~min}$ ) produced a robust and reversible increase in $\mathrm{GABA}_{\mathrm{A}}$-IPSC amplitude (Fig. $4 d, e ;+87.8 \pm 27.6 \%$, main effect of time, $\left.F_{(2,11)}=8.5, p=0.006\right)$. Bath application of the broad-spectrum neurotensin receptor (NTS1 and 2) antagonist SR-14298 (10 $\mu \mathrm{M})$ significantly reduced this response, suggesting that indeed a train of depolarization pulses triggers neurotensin release in the ovBNST (Fig. $4 d$; Time $\times$ Group, $\left.F_{(3,43)}=5.0, p=0.005\right)$. Similar to the pharmacological application of neurotensin, paired-pulse analyses suggested that depolarization-induced enhancement of $\mathrm{GABA}_{\mathrm{A}}$-IPSC was presynaptic (Fig. $4 e, f ; t_{6}=-4.1, p=0.006$ ). Therefore, it is likely that postsynaptic DRD1 activation triggers local neurotensin release, which then enhances the probability of GABA release and an increase in $\mathrm{GABA}_{\mathrm{A}}$-IPSC amplitude. We thus predicted that the NTS antagonist would prevent D1-LTP $\mathrm{GABA}_{\mathrm{G}}$ in slices prepared from Cocaine Maintenance rats, which was indeed the case (Fig. $4 g, h ; p=0.0001$ vs DRD1 activation alone). Although the effect of neurotensin lasted several minutes, the amplitude of $\mathrm{GABA}_{\mathrm{A}}$-IPSC inevitably returned to baseline (Fig. $4 a, d$ ). How- 
a

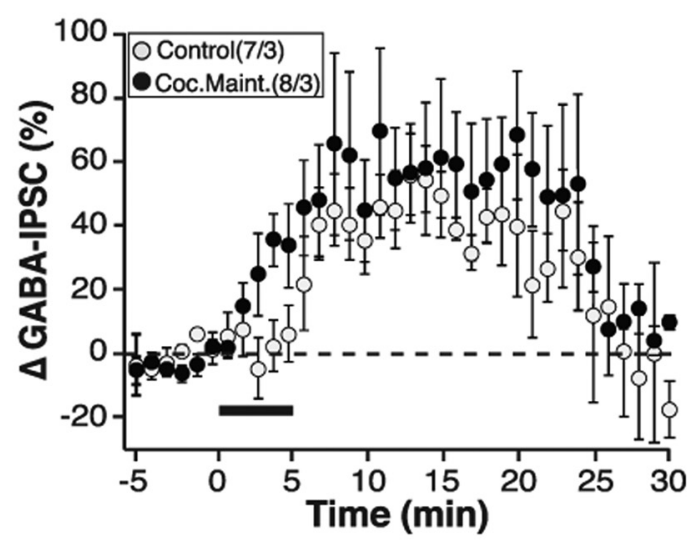

d

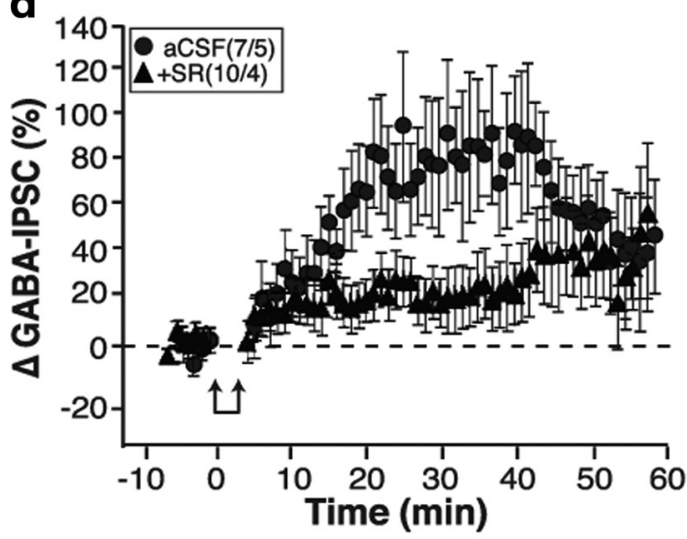

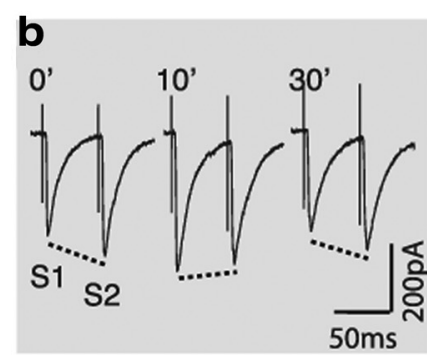

g

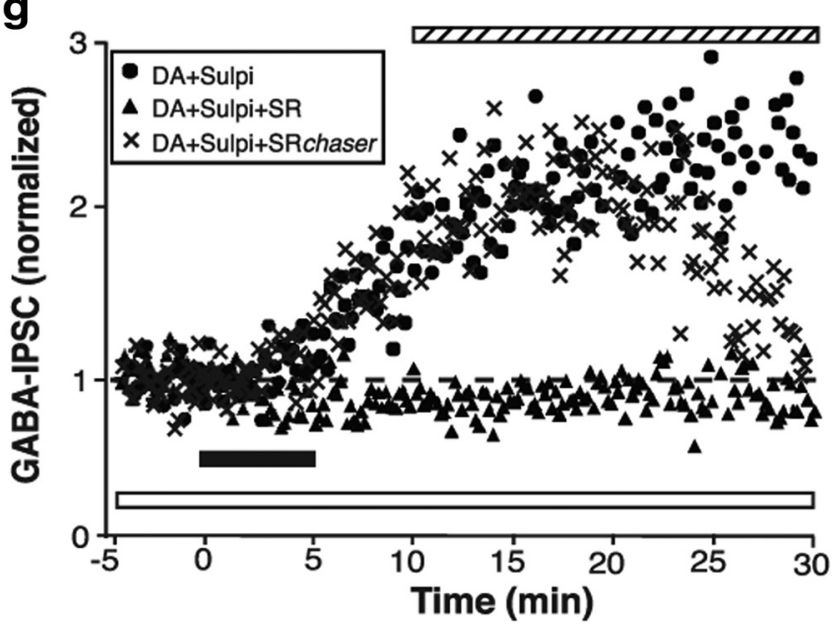

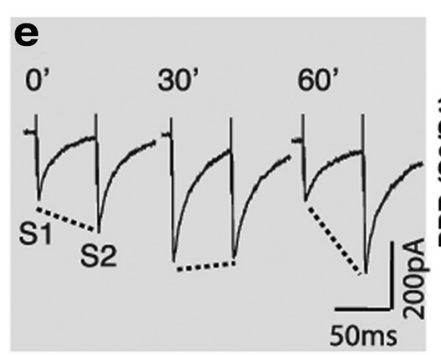

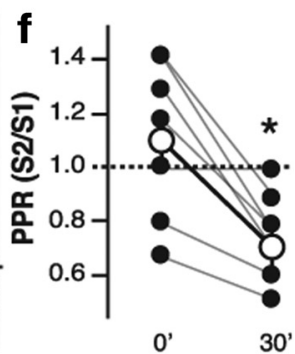

h

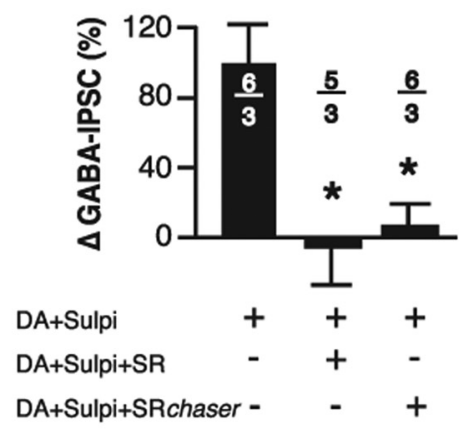

Figure 4. Role of neurotensin in ovBNST D1-LTP GABA $_{\boldsymbol{a}}$, Effect of neurotensin (black horizontal bar, $1 \mu \mathrm{m}$ ) on the amplitude of evoked GABA - -IPSC in ovBNST neurons of Control and Cocaine Maintenance rats as a function of time. Evoked events were binned ( $1 \mathrm{~min}, 6$ events) and data point and error bars represent means \pm SEM across all recorded neurons within each experimental group. Numbers in parentheses indicate sample size (neurons/rats). $\boldsymbol{b}$, Representative traces showing the effect of neurotensin on the amplitude and PPR of GABA - IPSC measured in ovBNST neurons of Cocaine Maintenance rats. S1 and S2 represent the maximum GABA - -IPSC amplitudes in response to two electrical stimulations given at $20 \mathrm{~Hz}$ to measure changes in PPR summarized in c. c, Summary of the effects of neurotensin on the PPR of GABA - IPSC in Cocaine Maintenance rats. Each black circle represents individual neurons and white circles are means \pm SEM of PPRs at times 0 and $10^{\prime}$. $\boldsymbol{d}$, Effect of postsynaptic depolarization $\left(-70\right.$ to $0 \mathrm{mV}, 100 \mathrm{~ms}, 2 \mathrm{~Hz}, 5 \mathrm{~min}$ ) on the amplitude of evoked $\mathrm{CABA}_{\mathrm{A}}-\mathrm{IPSC}$ as a function of time in ovBNST neurons of Cocaine Maintenance rats in the absence (circles) or presence (triangles) of the NTS antagonist SR-14298 (10 $\mu \mathrm{m}$ ). Evoked events were binned ( $1 \mathrm{~min}, 6$ events) and data point and error bars represent means \pm SEM across all recorded neurons. Numbers in parentheses indicate sample size (neurons/rats). $\boldsymbol{e}$, Representative traces showing the effect of postsynaptic depolarization on the amplitude and PPR of $G_{A B A_{A}-I P S C}$ measured in ovBNST neurons of Cocaine Maintenance rats. $\boldsymbol{f}$, Summary of the effects of neurotensin on the PPR of GABA - IPSC in Cocaine Maintenance rats. Each dot represents

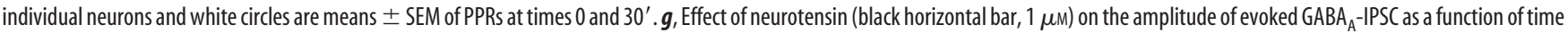
in ovBNST neurons of Cocaine Maintenance rats in the presence of the neurotensin receptor antagonistSR-14298 (10 $\mu \mathrm{M})$ applied throughout (gray bar) the recordings or at the peak (chaser, hatched bar) of the DRD1-mediated response. Each data point represents an electrically evoked $(0.1 \mathrm{~Hz}) G A B A_{A}-$ IPSC. $\boldsymbol{h}$, Bar chart summarizing the effects of the neurotensin antagonist SR-14298 (1 $\left.\mu \mathrm{M}\right)$ on

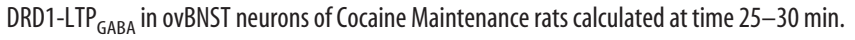

ever, the kinetic of this response suggested little desensitization such that a sustained release of neurotensin could potentially

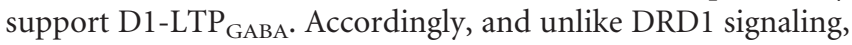
which we previously showed to be irreversible once activated (Fig. 2e), we predicted that we could chase $\mathrm{D} 1-\mathrm{LTP}_{\mathrm{GABA}}$ with a competitive NTS antagonist. As predicted, $\mathrm{GABA}_{\mathrm{A}}$-IPSC returned to baseline within $15 \mathrm{~min}$ of bath application of SR-14298

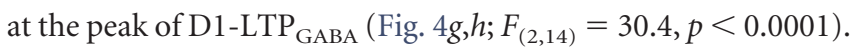
This experiment further supports sustained DRD1 signaling, resulting in a prolonged release of neurotensin that may trigger, per $s e$, reversible intracellular signaling in the presynaptic GABA terminal. In addition, neurotensin was equally efficacious at increasing $\mathrm{GABA}_{\mathrm{A}}$-IPSC in slices from Control and Cocaine Maintenance rats (Fig. 4a), such that we predicted that D1- 


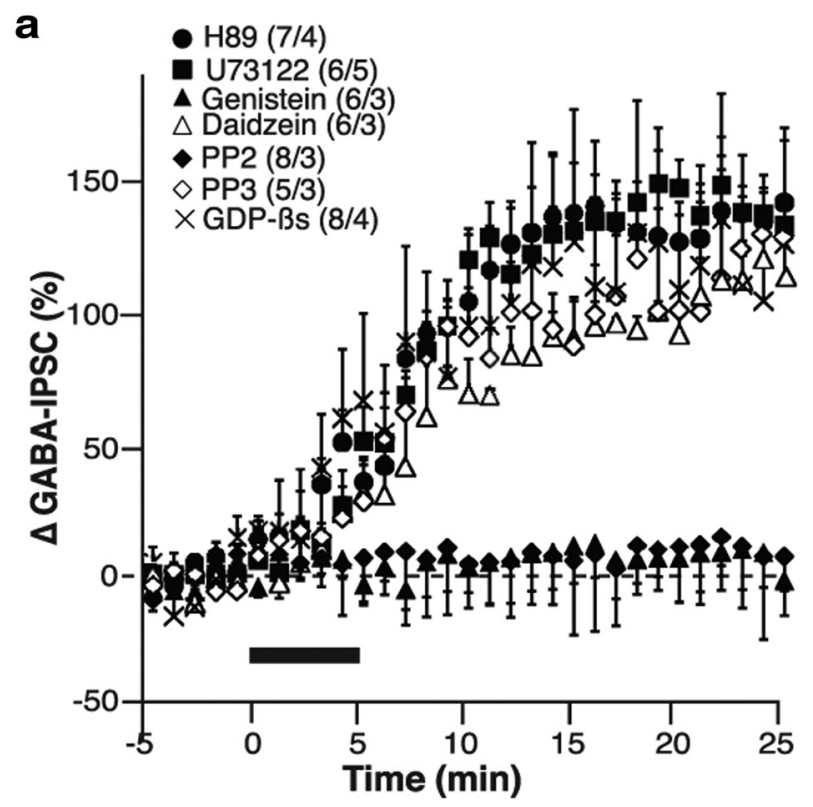

b

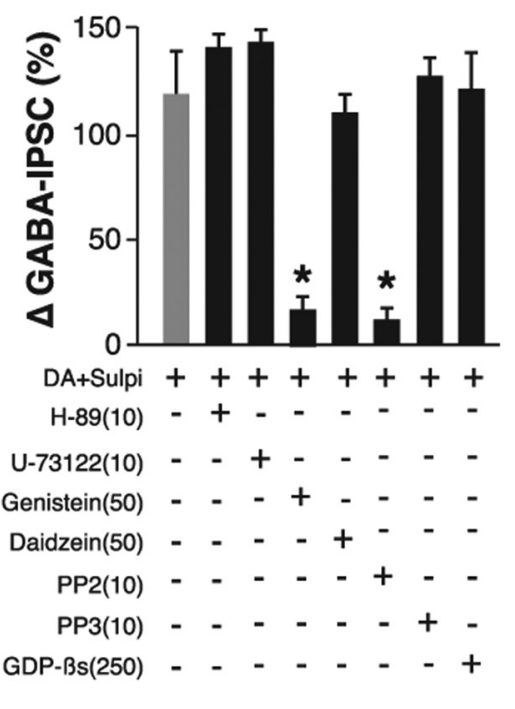

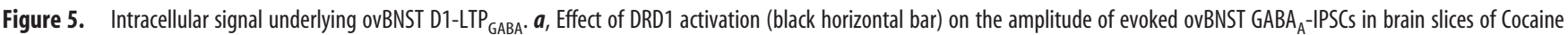
Maintenance rats. H89 (PKA inhibitor), U73122 (PLC inhibitor), genistein (TKinhibitor), daidzein (inactive analog of genistein), PP2 (c-Src inhibitor), PP3 (inactive analog of PP2), GDP- $\beta$ S (G-protein blocker) were added intracellularly and were thus present during the complete duration of the recordings. Evoked events were binned (1 min, 6 events) and data point and error bars represent means \pm SEM across all recorded neurons within each experimental group. Numbers in parentheses indicate the sample sizes (neurons/rats). $\boldsymbol{b}$, Bar charts summarizing the effects of signaling molecules (in $\mu \mathrm{M}$ ) and enzymes inhibitors on ovBNST D1-LTP ${ }_{G A B A}$. Data were calculated from the last 5 min of recording.

$\mathrm{LTP}_{\mathrm{GABA}}$ in Cocaine Maintenance rats resulted from mechanistic alterations upstream from NTS receptors activation. Accordingly, we next examined the signaling pathway recruited by DRD1 activation with pharmacological manipulations of the postsynaptic compartment by adding drugs in the recording (internal) solution, avoiding direct interference with putative presynaptic NTS signaling.

\section{DRD1-LTP ${ }_{\text {GABA }}$ involves c-Src TK signaling in a}

G-protein-independent fashion

The incorporation of various pharmacological blockers of signaling molecules and enzymes significantly interfered with D1-LTP ${ }_{\text {GABA }}$, confirming the postsynaptic location of DRD1 signaling and the specific pathways involved (main effect of pharmacological blockers on D1-LTP ${ }_{\mathrm{GABA}}$ amplitude at time 20-25 $\min ; F_{(7,54)}=5.01, p=0.0002$, Fig. 5). These data suggest that DRD1 coupled to intracellular signaling pathways that are, perhaps, self-sustaining once activated. There is little evidence that intracellular signals typically recruited by DRD1, such as adenylate cyclase/PKA or the PLC/PKC pathways (for review, see Neve et al., 2004), would support such a phenomenon. Accordingly, the addition of the PKA inhibitor H89 $(10 \mu \mathrm{M})$ or the PLC inhibitor U-73122 $(10 \mu \mathrm{M})$ to the intracellular solution did not affect

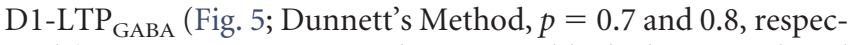
tively). In contrast, H89 and U-73122 blocked DA-mediated modulation of NMDAR-currents in these same neurons and conditions, confirming their efficacy at the chosen concentration, but also that DRD1 engages multiple signaling pathways to differently modulate excitatory and inhibitory transmission in these conditions (data not shown). D1-LTP GABA $_{\text {occurred de- }}$ spite the intracellular presence of the nonhydrolyzable GTP ana$\log$ GDP- $\beta s(250 \mu \mathrm{M})$, suggesting G-protein-independent DRD1 (Fig. 5; Dunnett's Method, $p=0.9$ ). We confirmed the efficacy of GDP- $\beta$ s at this concentration by blocking DRD2-mediated modulation of $\mathrm{GABA}_{\mathrm{A}}$-IPSC (data not shown) and D1/DRD2- mediated modulation of NMDA-EPSC (data not shown) in these same neurons and conditions.

In contrast to serine/threonine kinases, TKs typically contribute to long-lasting, self-sustaining biological responses (for review, see Luttrell et al., 1999a). Specifically, c-Src TKs contribute to the DRD1-induced increase in $\mathrm{GABA}_{\mathrm{A}}$-IPSC and trigger inhibitory oscillations in the mouse lateral amygdala in a putative G-protein-independent way (Lorétan et al., 2004). Here, the intracellular presence of the nonspecific TK inhibitor genistein (10 $\mu \mathrm{M})$ or the specific c-Src TK inhibitor PP2 $(10 \mu \mathrm{M})$ completely blocked D1-LTP ${ }_{\mathrm{GABA}}$ in Cocaine Maintenance rats (Fig. 5; Dunnett's Method, $p=0.02$ and 0.005 , respectively), whereas daidzein $(10 \mu \mathrm{M})$ and PP3 $(10 \mu \mathrm{M})$, inactive analogs of genistein and PP2, respectively, were ineffective (Fig. 5; Dunnett's Method, $p=$ 0.9 and 0.8 , respectively). Therefore, this series of experiments revealed the involvement of c-Src TK but also confirmed an obligatory role for postsynaptic activation of DRD1 in D1$\mathrm{LTP}_{\mathrm{GABA}}$ because intracellular pharmacological manipulations effectively blocked the response. Naturally, this series of experiments relies upon the specificity of all the pharmacological agents used, but we obtained several negative results, which reduces substantially the possibility of nonspecific effects.

\section{Discussion}

Brain slice voltage-clamp recordings of neurons in the ovBNST revealed DA DRD1-mediated long-lasting increases in $\mathrm{GABA}_{\mathrm{A}^{-}}$ IPSC amplitude (D1-LTP $\mathrm{GABA}_{\mathrm{G}}$ ) specifically in rats with prolonged cocaine self-administration experience. D1-LTP ${ }_{\mathrm{GABA}}$ resulted from increased GABA release involving local release of neurotensin after postsynaptic activation of G-proteinindependent and c-Src-dependent DRD1. Intra-ovBNST DRD1 blockade and D1-LTP $\mathrm{GABA}_{\mathrm{G}}$ magnitude were positively linked with lever pressing for cocaine on a PR schedule of reinforcement, revealing a novel neurophysiological mechanism of individual motivation to self-administer cocaine in rats (Fig. 6). 


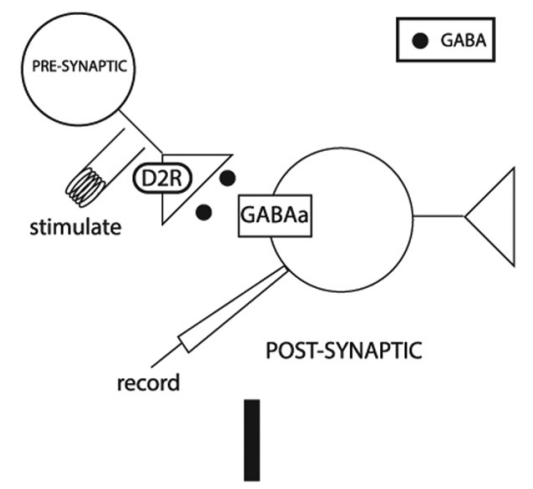

Prolonged cocaine self-administration

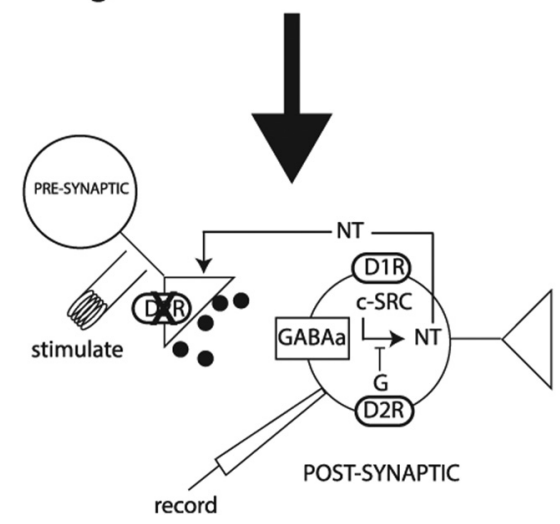

Figure 6. DA modulation of ovBNST GABA $A_{A}-$ IPSC before and after cocaine self-administration. In the ovBNST of Control rats, DA binds to presynaptic DRD2 and decreases GABA release, resulting in a reversible reduction in $\mathrm{GABA}_{A}-$ IPSC amplitude (Krawczyk et al., 2011a, 2011b). With a prolonged cocaine self-administration experience, presynaptic DRD2 receptors are substituted with postsynaptic DRD1 and DRD2 (Krawczyk et al., 2011b). The resulting effect of postsynaptic activation of DRD1 and DRD2 is DRD1-LTP ${ }_{G A B A}$, which involves c-Src-dependent release of neurotensin that increases presynaptic GABA release.

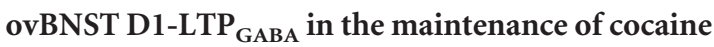
self-administration behaviors

Our data suggest that ovBNST D1-LTP $\mathrm{GABA}_{\mathrm{G}}$ may represent a mechanism underpinning the highest segment of lever pressing under the PR schedule of cocaine reinforcement. In an individual-sensitive way, this mechanism reveals a potential neural substrate of at least one defining element of compulsive cocaine intake in rats (Deroche-Gamonet et al., 2004; Vanderschuren and Everitt, 2004; Belin et al., 2008). ovBNST D1$\mathrm{LTP}_{\mathrm{GABA}}$ was not detectable after acquisition of cocaine self-administration, which may rule out its involvement in instrumental learning and in the response-outcome phase of instrumental operant behavior (Everitt and Robbins, 2005). Conversely, ovBNST D1-LTP $\mathrm{GABA}_{\mathrm{G}}$ seemed critical in the maintenance of cocaine self-administration once putatively switched to a more stimulus-response (S-R) scheme observed with prolonged training (Everitt and Robbins, 2005; Vanderschuren et al., 2005). DA signaling did not change with prolonged maintenance of sucrose self-administration, suggesting that sucrose-driven operant behavior may not strictly switch to S-R in our conditions. Therefore, ovBNST D1-LTP ${ }_{\mathrm{GABA}}$ may add a positive reinforcing signal energizing the S-R driven behavior (Robinson and Berridge, 1993). This would suggest that $\mathrm{S}-\mathrm{R}$ driven cocaine intake might not be dissociated from the incentive value of rewards (Robinson and Berridge, 1993). "Energized" S-R driven drug seeking and taking may support the switch to compulsive drug use in certain individuals and ovBNST DRD1 signaling might be an underlying mechanism. This hypothesis is supported by enhancement of lever pressing for cocaine on reward-rich schedules (initial portion of daily PR schedule in Fig. 1b, bottom; Fig. $1 c$, right; and Epping-Jordan et al., 1998) for the effect of intradlBNST SCH-23390 on FR-1) with intra-dlBNST DRD1 blockade and is indicative of a reduction in the reinforcing property of the reward. Although ovBNST D1-LTP $\mathrm{GABA}_{\mathrm{B}}$ is not restricted to a low contingency schedule of reinforcement, its magnitude seems critical in driving enhanced motivation to seek cocaine in the low contingency portion of the PR schedule of reinforcement (Epping-Jordan et al., 1998; Krawczyk et al., 2011a). Furthermore, ovBNST D1-LTP $\mathrm{GABA}_{\mathrm{G}}$ may also contribute in relapse to cocaine seeking, because $30 \mathrm{~d}$ of withdrawal did not reverse ovBNST DRD1 function (Krawczyk et al., 2011a). Whether the ovBNST contributes to the reinforcing properties of cocaine through positive or negative reinforcement (or both processes) is unclear and will necessitate further investigations (Koob and Le Moal, 2008).

\section{Cocaine self-administration alters ovBNST DA receptor expression and function}

Corroborating results from our previous study, we observed here that prolonged cocaine self-administration, but not similar passive exposure to cocaine, was accompanied by robust alterations in DA receptor expression and function in the ovBNST (Krawczyk et al., 2011a). Under normal (physiological) conditions, the primary synaptic effect of DA in the ovBNST is to reduce GABA release through the activation of presynaptic DRD2 (Krawczyk et al., 2011a, 2011b). This DRD2 response becomes dysfunctional in rats with a prolonged cocaine self-administration experience, which is consistent with observations made in striatal regions across several species, including humans (Volkow et al., 1993; Nader et al., 2006).

In rats with a prolonged cocaine self-administration experience, our experiments show a reversal in DA-mediated modulation of $\mathrm{GABA}_{\mathrm{A}}$ currents, from reduction to enhancement, through a robust shift toward DRD1-mediated signaling over DRD2 (Krawczyk et al., 2011a). Our functional and anatomical data show weak levels of DRD1 in the ovBNST of Control rats, suggesting transcriptional or posttranscriptional events resulting in enhanced expression of DRD1 in Cocaine rats. However, we measured comparable levels of DRD1 mRNA, suggesting posttranslational events consistent with other hyperdopaminergic conditions (Aubert et al., 2005; Berthet et al., 2009).

\section{D1-LTP ${ }_{\mathrm{GABA}}$ involves local neurotensin release}

PPR measures and CV analyses both confirmed our previous conclusions that DRD1-mediated enhancement of ovBNST $\mathrm{GABA}_{\mathrm{A}}$-IPSC in Cocaine Maintenance rats results from an increase in presynaptic GABA release (Krawczyk et al., 2011a). This observation challenged our initial prediction that interactions between DRD1 and $\mathrm{GABA}_{\mathrm{A}}$ could occur postsynaptically. This prediction was made from three observations: (1) in Cocaine Maintenance rats, we detected DRD1 immunohistochemical products in perikarya and primary dendrites of ovBNST neurons (Fig. 3); (2) applications of certain pharmacological agents into the postsynaptic compartment completely blocked D1-LTP $\mathrm{GABA}_{\mathrm{G}}$ (Fig. 5); and (3) tyrosine phosphorylation of $\mathrm{GABA}_{\mathrm{A}}$ channels increased currents in heterologous and primary culture models (Wan et al., 1997). Despite overwhelming evidence for a presynaptic expression of D1-LTP $\mathrm{GABA}_{\mathrm{G}}$ but postsynaptic anatomical location of DRD1, we tested the alternative hypothesis for the involvement of a retrograde synaptic messenger. Our results 
show that neurotensin links postsynaptic DRD1 activation with presynaptic enhancement of GABA release. Although our data confirm that postsynaptic depolarization can trigger neurotensin release, we cannot determine whether this release is somatodendritic or axonal because the ovBNST contains short-axon neurons such that neurotensin could be released synaptically at the axon terminal to contact presynaptic GABA terminals (LarrivaSahd, 2006). Alternatively, somatodendritic release of neurotensin would support recent evidence that synaptic retrograde messaging is not solely restricted to small liposoluble molecules (e.g., NO, endocannabinoids) but can also be carried by neuropeptides. Nonetheless, our experiments show that neurotensin can act as a local modulator of synaptic transmission (Rakovska et al., 1998; Petrie et al., 2005). However, ovBNST NT mRNA levels are under positive mesolimbic DA regulation such that an enhancement of NT levels may be at play in Cocaine Maintenance rats (Day et al., 2002). The abolition of D1-LTP $\mathrm{GABA}_{\mathrm{G}}$ by an NTS antagonist suggests that neurotensin is an important contributor in the maintenance of cocaine self-administration behaviors. Accordingly, many studies examining the link between neurotensin and the behavioral effects of drugs of abuse suggest an enhancing effect of neurotensin on the reinforcing properties of psychostimulants (Ervin et al., 1981; Lopak and Erb, 2005; Torregrossa and Kalivas, 2008).

\section{c-Src TKs underlie the long-lasting profile of ovBNST D1-LTP ${ }_{\text {GABA }}$}

Upon brief DRD1 activation, DRD1 ligands were no longer required to sustain D1-LTP $\mathrm{GABA}_{\mathrm{G}}$. Specifically, we showed that preapplying the DRD1 antagonist SCH-23390 prevented D1$\mathrm{LTP}_{\mathrm{GABA}}$, whereas SCH could not reverse it once initiated. This suggests that the mechanism(s) underlying the long-lasting profile of D1-LTP ${ }_{\mathrm{GABA}}$ most likely occurs downstream of DRD1 activation. Because the effect of neurotensin on GABA release was transient (Fig. 4a), we suspected that c-Src activation might be the self-sustaining element in the sequence of signaling events. Consistent with this hypothesis, c-Src TK activity is selfsustaining through autophosphorylation of Tyr418 (for review, see Boggon and Eck, 2004). Moreover, recent evidence supports a role for these enzymes in drug-driven behaviors (Narita et al., 2006).

Metabotropic receptors, including DRD1, can trigger intracellular signaling independently of G-proteins (Lee et al., 2002; Lorétan et al., 2004; Wang et al., 2008). To investigate the contribution of G-protein in D1-LTP ${ }_{\mathrm{GABA}}$, we used the nonhydrolyzable GTP analog GDP- $\beta$ s intracellularly in the micromolar range (Kotecha et al., 2002; Martina and Bergeron, 2008). GDP- $\beta$ s was potent in our preparation because it completely blocked DRD2dependent modulation of $\mathrm{GABA}_{\mathrm{A}}$-IPSC and DRD1/DRD2dependent modulation of NMDA-EPSC in the same ovBNST neuronal population and identical conditions when applied intracellularly (i.e., in the postsynaptic compartment, data not shown). G-protein-independent signaling often occurs through protein-protein interaction processes (Luttrell et al., 1999b; Kim et al., 2004). Because there is no evidence of direct proteinprotein interaction between metabotropic receptors and c-Src TK, adaptor proteins (e.g., arrestins) may link DRD1 with c-Src activity (Luttrell et al., 1999b; Macey et al., 2005).

Our study reveals a complex rearrangement in DA signaling and a complete reversal in $\mathrm{DA}$ modulation of $\mathrm{GABA}_{\mathrm{A}}$-mediated synaptic transmission with a prolonged cocaine self-administration experience. Accordingly, DA in the ovBNST seems to completely change neurophysiological allegiance from a powerful physiological DRD2- mediated reduction (in $\mathrm{GABA}_{\mathrm{A}}$ synaptic transmission) to a longlasting enhancement in $\mathrm{GABA}_{\mathrm{A}}$ transmission mediated by DRD1 in cocaine self-administering rats. Above a certain magnitude, the DRD1-mediated response becomes significant in underlying the maladaptive enhanced effort certain rats are willing to spend to obtain cocaine on the PR schedule of reinforcement. Therefore, our study revealed a novel and complex neural mechanism that may play a critical role in at least one aspect of compulsive cocaine intake in rats and may contribute to addictive behaviors. Future studies should investigate the possible contribution of ovBNST D1$\mathrm{LTP}_{\mathrm{GABA}}$ in other elements of compulsive cocaine intake (DerocheGamonet et al., 2004; Vanderschuren and Everitt, 2004; Belin et al., 2008 ) and determine whether ovBNST D1-LTP ${ }_{\mathrm{GABA}}$ is a key neurophysiological mechanism that represents a potential therapeutic target for human addiction.

\section{References}

Andrzejewski ME, Spencer RC, Kelley AE (2005) Instrumental learning, but not performance, requires dopamine D1-receptor activation in the amygdala. Neuroscience 135:335-345. CrossRef Medline

Aubert I, Guigoni C, Håkansson K, Li Q, Dovero S, Barthe N, Bioulac BH, Gross CE, Fisone G, Bloch B, Bézard E (2005) Increased D1 dopamine receptor signaling in levodopa-induced dyskinesia. Ann Neurol 57:17-26. CrossRef Medline

Belin D, Mar AC, Dalley JW, Robbins TW, Everitt BJ (2008) High impulsivity predicts the switch to compulsive cocaine-taking. Science 320:13521355. CrossRef Medline

Berthet A, Porras G, Doudnikoff E, Stark H, Cador M, Bézard E, Bloch B (2009) Pharmacological analysis demonstrates dramatic alteration of D1 dopamine receptor neuronal distribution in the rat analog of L-DOPAinduced dyskinesia. J Neurosci 29:4829-4835. CrossRef Medline

Boggon TJ, Eck MJ (2004) Structure and regulation of Src family kinases. Oncogene 23:7918-7927. CrossRef Medline

Carboni E, Silvagni A, Rolando MT, Di Chiara G (2000) Stimulation of in vivo dopamine transmission in the bed nucleus of stria terminalis by reinforcing drugs. J Neurosci 20:RC102. Medline

Day HE, Curran EJ, Watson SJ Jr, Akil H (1999) Distinct neurochemical populations in the rat central nucleus of the amygdala and bed nucleus of the stria terminalis: evidence for their selective activation by interleukin1beta. J Comp Neurol 413:113-128. CrossRef Medline

Day HE, Vittoz NM, Oates MM, Badiani A, Watson SJ Jr, Robinson TE, Akil H (2002) A 6-hydroxydopamine lesion of the mesostriatal dopamine system decreases the expression of corticotropin releasing hormone and neurotensin mRNAs in the amygdala and bed nucleus of the stria terminalis. Brain Res 945:151-159. CrossRef Medline

Deroche-Gamonet V, Belin D, Piazza PV (2004) Evidence for addiction-like behavior in the rat. Science 305:1014-1017. CrossRef Medline

Dumont EC, Williams JT (2004) Noradrenaline triggers GABAA inhibition of bed nucleus of the stria terminalis neurons projecting to the ventral tegmental area. J Neurosci 24:8198-8204. CrossRef Medline

Eiler WJ II, Seyoum R, Foster KL, Mailey C, June HL (2003) D1 dopamine receptor regulates alcohol-motivated behaviors in the bed nucleus of the stria terminalis of alcohol-preferring rats. Synapse 48:45-56. CrossRef Medline

Epping-Jordan MP, Markou A, Koob GF (1998) The dopamine D-1 receptor antagonist SCH 23390 injected into the dorsolateral bed nucleus of the stria terminalis decreased cocaine reinforcement in the rat. Brain Res 784:105-115. CrossRef Medline

Ervin GN, Birkemo LS, Nemeroff CB, Prange AJ Jr (1981) Neurotensin blocks certain amphetamine-induced behaviours. Nature 291:73-76. CrossRef Medline

Everitt BJ, Robbins TW (2005) Neural systems of reinforcement for drug addiction: from actions to habits to compulsion. Nat Neurosci 8:14811489. CrossRef Medline

Faber DS, Korn H (1991) Applicability of the coefficient of variation method for analyzing synaptic plasticity. Biophys J 60:1288-1294. CrossRef Medline

Fuxe K, Von Euler G, Agnati LF, Merlo Pich E, O'Connor WT, Tanganelli S, Li XM, Tinner B, Cintra A, Carani C, et al. (1992) Intramembrane interactions between neurotensin receptors and dopamine $\mathrm{D} 2$ receptors as 
a major mechanism for the neuroleptic-like action of neurotensin. Ann N Y Acad Sci 668:186-204. CrossRef Medline

Guigoni C, Doudnikoff E, Li Q, Bloch B, Bézard E (2007) Altered D(1) dopamine receptor trafficking in parkinsonian and dyskinetic nonhuman primates. Neurobiol Dis 26:452-463. CrossRef Medline

Hyytiä P, Koob GF (1995) GABAA receptor antagonism in the extended amygdala decreases ethanol self-administration in rats. Eur J Pharmacol 283:151-159. CrossRef Medline

Kash TL, Winder DG (2006) Neuropeptide Y and corticotropin-releasing factor bi-directionally modulate inhibitory synaptic transmission in the bed nucleus of the stria terminalis. Neuropharmacology 51:1013-1022. CrossRef Medline

Kim OJ, Gardner BR, Williams DB, Marinec PS, Cabrera DM, Peters JD, Mak CC, Kim KM, Sibley DR (2004) The role of phosphorylation in D1 dopamine receptor desensitization: evidence for a novel mechanism of arrestin association. J Biol Chem 279:7999-8010. CrossRef Medline

Koob GF, Le Moal M (2008) Review. Neurobiological mechanisms for opponent motivational processes in addiction. Philos Trans R Soc Lond B Biol Sci 363:3113-3123. CrossRef Medline

Kotecha SA, Oak JN, Jackson MF, Perez Y, Orser BA, Van Tol HH, MacDonald JF (2002) A D2 class dopamine receptor transactivates a receptor tyrosine kinase to inhibit NMDA receptor transmission. Neuron 35: 1111-1122. CrossRef Medline

Krawczyk M, Sharma R, Mason X, Debacker J, Jones AA, Dumont EC (2011a) A switch in the neuromodulatory effects of dopamine in the oval bed nucleus of the stria terminalis associated with cocaine selfadministration in rats. J Neurosci 31:8928-8935. CrossRef Medline

Krawczyk M, Georges F, Sharma R, Mason X, Berthet A, Bézard E, Dumont EC (2011b) Double-dissociation of the catecholaminergic modulation of synaptic transmission in the oval bed nucleus of the stria terminalis. J Neurophysiol 105:145-153. CrossRef Medline

Larriva-Sahd J (2006) Histological and cytological study of the bed nuclei of the stria terminalis in adult rat. II. Oval nucleus: extrinsic inputs, cell types, neuropil, and neuronal modules. J Comp Neurol 497:772-807. CrossRef Medline

Lee FJ, Xue S, Pei L, Vukusic B, Chéry N, Wang Y, Wang YT, Niznik HB, Yu XM, Liu F (2002) Dual regulation of NMDA receptor functions by direct protein-protein interactions with the dopamine D1 receptor. Cell 111:219-230. CrossRef Medline

Levey AI, Hersch SM, Rye DB, Sunahara RK, Niznik HB, Kitt CA, Price DL, Maggio R, Brann MR, Ciliax BJ (1993) Localization of D1 and D2 dopamine receptors in brain with subtype-specific antibodies. Proc Natl Acad Sci U S A 90:8861-8865. CrossRef Medline

Li C, Pleil KE, Stamatakis AM, Busan S, Vong L, Lowell BB, Stuber GD, Kash TL (2012) Presynaptic inhibition of gamma-aminobutyric acid release in the bed nucleus of the stria terminalis by kappa opioid receptor signaling. Biological psychiatry 71:725-732. CrossRef Medline

Lopak V, Erb S (2005) Activation of central neurotensin receptors reinstates cocaine seeking in the rat: modulation by a D1/D5, but not D2/D3, receptor antagonist. Psychopharmacology (Berl) 182:297-304. CrossRef Medline

Lopez-Grancha M, Lopez-Crespo G, Sanchez-Amate MC, Flores P (2008) Individual differences in schedule-induced polydipsia and the role of gabaergic and dopaminergic systems. Psychopharmacology (Berl) 197:487-498. CrossRef Medline

Lorétan K, Bissière S, Lüthi A (2004) Dopaminergic modulation of spontaneous inhibitory network activity in the lateral amygdala. Neuropharmacology 47:631-639. CrossRef Medline

Luttrell LM, Daaka Y, Lefkowitz RJ (1999a) Regulation of tyrosine kinase cascades by G-protein-coupled receptors. Curr Opin Cell Biol 11:177-183. CrossRef Medline

Luttrell LM, Ferguson SS, Daaka Y, Miller WE, Maudsley S, Della Rocca GJ, Lin F, Kawakatsu H, Owada K, Luttrell DK, Caron MG, Lefkowitz RJ (1999b) Beta-arrestin-dependent formation of beta2 adrenergic receptor-Src protein kinase complexes. Science 283:655-661. CrossRef Medline

Macey TA, Liu Y, Gurevich VV, Neve KA (2005) Dopamine D1 receptor interaction with arrestin3 in neostriatal neurons. J Neurochem 93:128-134. CrossRef Medline

Martina M, Bergeron R (2008) D1 and D4 dopaminergic receptor interplay mediates coincident $\mathrm{G}$ protein-independent and dependent regulation of glutamate NMDA receptors in the lateral amygdala. J Neurochem 106: 2421-2435. CrossRef Medline

Nader MA, Daunais JB, Moore T, Nader SH, Moore RJ, Smith HR, Friedman DP, Porrino LJ (2002) Effects of cocaine self-administration on striatal dopamine systems in rhesus monkeys: initial and chronic exposure. Neuropsychopharmacology 27:35-46. CrossRef Medline

Nader MA, Morgan D, Gage HD, Nader SH, Calhoun TL, Buchheimer N, Ehrenkaufer R, Mach RH (2006) PET imaging of dopamine D2 receptors during chronic cocaine self-administration in monkeys. Nat Neurosci 9:1050-1056. CrossRef Medline

Narita M, Kato H, Kasukawa A, Narita M, Suzuki M, Takeuchi T, Suzuki T (2006) Role of Src family kinase in the rewarding effect and hyperlocomotion induced by morphine. Neuroreport 17:115-119. CrossRef Medline

Neve KA, Seamans JK, Trantham-Davidson H (2004) Dopamine receptor signaling. J Recept Signal Transduct Res 24:165-205. CrossRef Medline

Nugent FS, Hwong AR, Udaka Y, Kauer JA (2008) High-frequency afferent stimulation induces long-term potentiation of field potentials in the ventral tegmental area. Neuropsychopharmacology 33:1704-1712. CrossRef Medline

O’Connor WT, Tanganelli S, Ungerstedt U, Fuxe K (1992) The effects of neurotensin on GABA and acetylcholine release in the dorsal striatum of the rat: an in vivo microdialysis study. Brain Res 573:209-216. CrossRef Medline

Paxinos G, Watson C (2005) The rat brain in stereotaxic coordinates, Ed 5. San Diego: Academic.

Petrie KA, Schmidt D, Bubser M, Fadel J, Carraway RE, Deutch AY (2005) Neurotensin activates GABAergic interneurons in the prefrontal cortex. J Neurosci 25:1629-1636. CrossRef Medline

Pezük P, Göz D, Aksoy A, Canbeyli R (2006) BNST lesions aggravate behavioral despair but do not impair navigational learning in rats. Brain Res Bull 69:416-421. CrossRef Medline

Pezze MA, Dalley JW, Robbins TW (2007) Differential roles of dopamine D1 and D2 receptors in the nucleus accumbens in attentional performance on the five-choice serial reaction time task. Neuropsychopharmacology 32:273-283. CrossRef Medline

Rakovska A, Giovannini MG, Della Corte L, Kalfin R, Bianchi L, Pepeu G (1998) Neurotensin modulation of acetylcholine and GABA release from the rat hippocampus: an in vivo microdialysis study. Neurochem Int 33: 335-340. CrossRef Medline

Richardson NR, Roberts DC (1996) Progressive ratio schedules in drug selfadministration studies in rats: a method to evaluate reinforcing efficacy. J Neurosci Methods 66:1-11. CrossRef Medline

Robinson TE, Berridge KC (1993) The neural basis of drug craving: an incentive-sensitization theory of addiction. Brain Res Brain Res Rev 18: 247-291. CrossRef Medline

Schulz D, Canbeyli RS (2000) Lesion of the bed nucleus of the stria terminalis enhances learned despair. Brain Res Bull 52:83-87. CrossRef Medline

Torregrossa MM, Kalivas PW (2008) Neurotensin in the ventral pallidum increases extracellular gamma-aminobutyric acid and differentially affects cue- and cocaine-primed reinstatement. J Pharmacol Exp Ther 325: 556-566. CrossRef Medline

van Kuyck K, Brak K, Das J, Rizopoulos D, Nuttin B (2008) Comparative study of the effects of electrical stimulation in the nucleus accumbens, the mediodorsal thalamic nucleus and the bed nucleus of the stria terminalis in rats with schedule-induced polydipsia. Brain Res 1201:93-99. CrossRef Medline

Vanderschuren LJ, Everitt BJ (2004) Drug seeking becomes compulsive after prolonged cocaine self-administration. Science 305:1017-1019. CrossRef Medline

Vanderschuren LJ, Di Ciano P, Everitt BJ (2005) Involvement of the dorsal striatum in cue-controlled cocaine seeking. J Neurosci 25:8665-8670. CrossRef Medline

Volkow ND, Fowler JS, Wang GJ, Hitzemann R, Logan J, Schlyer DJ, Dewey SL, Wolf AP (1993) Decreased dopamine D2 receptor availability is associated with reduced frontal metabolism in cocaine abusers. Synapse 14:169-177. CrossRef Medline

Wan Q, Man HY, Braunton J, Wang W, Salter MW, Becker L, Wang YT (1997) Modulation of GABAA receptor function by tyrosine phosphorylation of beta subunits. J Neurosci 17:5062-5069. Medline

Wang M, Lee FJ, Liu F (2008) Dopamine receptor interacting proteins 
(DRIPs) of dopamine D1-like receptors in the central nervous system. Mol Cells 25:149-157. Medline
Zucker RS (1989) Short-term synaptic plasticity. Annu Rev Neurosci 12: 13-31. CrossRef Medline 